\title{
Research Article \\ Effect of Gap and Shims on the Strain and Stress State of the Composite-Aluminum Hybrid Bolted Structure
}

\author{
Xuande Yue $\mathbb{D}^{1},{ }^{1}$ Luling An $\left(\mathbb{D},{ }^{1}\right.$ Xin Ye, ${ }^{1}$ Chufan Wang, ${ }^{1}$ Yuebo Cai, ${ }^{1}$ and Ruiheng Xiao ${ }^{2}$ \\ ${ }^{1}$ College of Mechanical and Electrical Engineering, Nanjing University of Aeronautics and Astronautics, Nanjing 210016, China \\ ${ }^{2}$ Shanghai Aircraft Manufacturing Co., Ltd, Shanghai 200436, China
}

Correspondence should be addressed to Luling An; anllme@nuaa.edu.cn

Received 13 August 2020; Revised 30 October 2020; Accepted 15 November 2020; Published 9 December 2020

Academic Editor: Jose Carlos Páscoa

Copyright (C) 2020 Xuande Yue et al. This is an open access article distributed under the Creative Commons Attribution License, which permits unrestricted use, distribution, and reproduction in any medium, provided the original work is properly cited.

\begin{abstract}
The composite-aluminum hybrid bolted structures are widely used in aircraft. Due to low molding accuracy of composite components, gaps always occur between components during assembly. In this case, the bolt connection can cause a complex strain and stress state of component. It may adversely affect the mechanical properties or cause local damage of the structure. A simplified model of the composite-aluminum assembly structure was established in this paper. Then, the influence of forced assembly, liquid shim, and peelable fiberglass shim on the strain and stress state of the composite-aluminum hybrid bolted structure was studied. A bolt connection experimental device was designed to apply a preload to the specimen. The strain field on the specimen surface was measured using the 3D-DIC strain measurement system. The finite element model was established to study the interlaminar stress and damage state of composite laminates. It is found that the strain of specimen in the $X$ -direction is mainly affected by the bending deformation, while the strain in the $Y$-direction is mainly affected by the compression of bolt head. For composite laminates, the strain value in the $X$-direction can be reduced by $8.31 \%-70.97 \%$ with shims. As for the strain value in the $Y$-direction, the liquid shim can only reduce it up to $23.93 \%$ when the gap is large. In addition, the liquid shim and peelable fiberglass shim cannot reduce the stress value of all interlaminar elements, but it can make the stress distribution more uniform and improve the stress state of the interlaminar element when the shim was more than $0.8 \mathrm{~mm}$.
\end{abstract}

\section{Research Background}

Composite materials have been widely used in aircraft structures due to their excellent mechanical properties. The proportion of composite materials used in the Boeing 787 is as high as $50 \%$, while that of Airbus A350 can up to 52\% [1]. The widespread use of composite materials can significantly reduce weight and improve performance of aircrafts. Therefore, the proportion of composite materials has become an important indicator of the advanced aircraft. Despite the increasing use of composite materials, there are still a large number of metal structures in existing aircraft structures, including aluminum alloys and titanium alloys. Therefore, a large amount of the composite-metal hybrid bolted structure exists in the aircraft. For example, the hybrid connections exist between metal lug and composite spar between the wing and fuselage. What is more, they also exist in metal ribs and composite panel in the wing box.

The metal structure is mainly manufactured by the $\mathrm{CNC}$ (computer numerical control) machine, which has high geometric and dimensional precision and surface quality. Composite components are mostly formed using autoclave. The thermal expansion coefficients of fiber and resin are inconsistent, and that of composite and molds are also quite different. Therefore, the composite components tend to have a large deformation after molding, and interference or gap is often generated between assembly components [2]. The interference between components can be eliminated by milling the metal component or sacrificial layer of composite. As the gap is generated, the gap filling method should be determined according to the size of gap. Finally, the hole drilling operation and bolt connection are performed. During the bolt 
tightening process, the components are connected as a whole structure by applying a preload by fasteners. So, a significant bending deformation appears in components under preload when there is a gap in assembly structures. This may cause local stress concentration around the bolt hole, and interlaminar stress can increase in some areas. Sometimes, it may even cause local delamination of composite laminates. It can lead to a reduction in stiffness and load bearing capacity and affect the safety and reliability of assembly structure. This situation can be alleviated by applying shims. However, the shim material is different from assembly components, and their structural characteristics and mechanical properties are quite different. Therefore, the gap filling may have complicated effects on the strain and stress state of assembly structures.

At present, the research on gap filling in assembly of aircraft composite components mainly focuses on the following aspects: gap prediction and 3D model establishment, analysis of stress and strain state during assembly, and the influence of gap filling on the mechanical properties of structures.

Manohar et al. [3] proposed a shim prediction technique based on machine learning and sparse sensing for the complicated and cumbersome problem of gap filling work. Lacroix et al. [4] developed a numerical method to predict the size and distribution of the gap before assembly by measuring the shape of components. Falgarone et al. [5] developed ANATOLEFLEX software and used it to simulate the assembly process of nonrigid parts. Ehmke et al. [6] proposed an automatic gap filling method used in the assembly of large composite components for aircraft. The operation process includes component surface scanning, virtual assembly, 3D model calculation of gaps, and gap filling. Schmick et al. [7] proposed an algorithm for generating solid shim using $3 \mathrm{D}$ printing technology in automated assembly processes. Zaitseva et al. [8] developed ASRP software for simulation and process optimization of aircraft assembly. This software can analyze the point cloud of initial gap between the components and calculate the size and distribution of the gap after assembly, so as to determine the gap filling method. Bakker et al. [9] developed a new general method to predict the assembly gap between components and estimates the number of shims required. Wang et al. [10] proposed a gap filling method based on scan data and finite element analysis for the uneven gaps appearing during the assembly of aircraft wing box. Liu et al. [11] developed a numerical method for predicting gaps. Each assembly components are scanned, and scan data are used to generate a finite element mesh. The geometry of the assembly gap is obtained through virtual assembly. D' Angelo et al. [12] used eddy current testing (ECT) to measure the gaps between composite components due to molding and assembly deviations. Wang et al. [13] proposed an optimal posture evaluation model to control the gaps in the assembly work. As the gap reaches the minimum value and it is within the tolerance range, the component reaches the optimal posture [4].

Dong et al. [14] established a parametric finite element model for the assembly problem of composite and metal structures. The distribution of assembly stress was obtained by Monte Carlo analysis. Söderberg et al. [15] used the influ- ence coefficient method to establish a response model between composite wing rib assembly stresses and part manufacturing deviations. The Tsai-Hill failure criterion was used to characterize the magnitude of assembly stress. Chang et al. [16] studied the effects of different bolt tightening sequences and installation torques on the stress distribution of composite using a composite wing box with gap. The article points out that it is not possible to completely eliminate the gap by relying on the bolt preload without a shim. Chang et al. [17] investigated the influence of assembly gap on the final deformation of the assembly structure. Experiments showed that hybrid shim has a better effect of suppressing deformation, and the maximum strain can be reduced by about $20 \%$. Attahu et al. [18] and Ye et al. [19] studied the influence of gap and shims on stress and strain of composite-aluminum alloy assembly structures during bolted connections. The results showed both liquid shim and peelable shim can significantly reduce assembly stress and strain.

Zhai et al. [20] studied the effect of gap filling on the mechanical properties of composite-aluminum, single-lap, single-bolt joints in experiments. They compared the differences between forced assembly and different shims. Zhai et al. [21] also used a finite element method to study the three-dimensional stress distribution of the bolted joint under tension in forced assembly and gap filling. Liu et al. [22] used experimental and simulation methods to study the influence of liquid shim on the mechanical properties of composite-titanium joints. Liu [23] also pointed out that the influence of liquid shim on the performance of the assembly structure depends not only on the thickness and mechanical properties of liquid shim but also the stiffness of substrate. Comer et al. [24] studied the influence of aviation-grade liquid shim on the mechanical properties of composite-titanium, double-bolt, single-lap joints. Studies showed that the stiffness of liquid shim do not decrease in experiment while the contact surface do not fail. Hühne et al. [25] used finite element simulation to study the influence of liquid shim on the mechanical properties of composite single-lap single-bolt joints. Dhôte et al. [26] studied the influence of liquid shim on the mechanical properties of composite single-lap joints and composite-aluminum single-lap joints. Yang et al. [27] studied composite singlelap joints containing gaps and shim. An improved springmass model is proposed for the prediction of joint stiffness. Yang et al. [28] also investigated the influence of gap and shim on bending properties of composite joints. The effects of factors such as the gap size, shim material, shim percentage, and the gap between bolt and hole were studied. Cheng et al. [29] pointed out that shim can reduce the assembly stress of aluminum joints and improve stiffness and load carrying capacity. Attahu et al. [30] found that liquid shim can prolong the service life of the structure within a certain thickness range. Landström [31] used a finite element method to study the effect of liquid shim on the bearing capacity of composite bolted structures. Stocchi [32] studied the mechanical properties of double-bolt single-lap CFRP joints with countersunk holes, including tensile properties and fatigue properties. A detailed 3D finite element model was established during 
research. On this basis, some scholars carried out research on composite-metal hybrid bolted joint structures and delamination of composite laminate. Sellitto et al. [33] studied the tensile mechanical properties of metal-composite stiffened panel. The results show that the Omega stringer joints can inhibit the expansion of debonding, thereby avoiding the sudden reduction of the structural bearing capacity. Matsuzaki et al. [34] studied the effect of the bolted/cocured hybrid jointing method on the mechanical properties of compositealuminum joints. Compared with bolted connection, the new connection method can reduce stress concentration and fiber damage. Riccio [35] studied the effect of delamination on the compressive mechanical properties of composite laminate through experiments and simulations. Studies show that fiber bridging phenomenon is a natural toughening mechanism that can improve the interlayer strength of composite laminates. Davim et al. [36] analyzed the cutting parameters of drilling holes in composite laminates. The relationship of cutting velocity and feed rate with delamination of composite laminates was established using the Taguchi method and analysis of variance. Russo [37] studied the effect of fiber bridging on the delamination of reinforced composite stiffened panels. The results of the three-point bending experiment show that fiber bridging can significantly slow down the debonding between the skin and reinforcements.

Many researchers have studied the problem of gap filling, but there are still many issues need to be investigated. At present, most researches of gap filling have focused on the influence of shims on mechanical properties of assembly structures, including tensile and fatigue properties. However, there is a lack of research on the assembly process, especially the bolt tightening process. Preload is introduced to the assembly structures in the bolt tightening process, and it results in assembly strain and stress. They have a significant impact on the performance of the assembly structure. Therefore, it is necessary to study the strain and stress generated in assembly work.

The composite-aluminum hybrid bolted assembly model was built in this paper by analyzing a typical aircraft wing box structure. A bolt connection experimental device was designed to apply preload to the assembly model. The strain and stress state of the specimen under forced assembly, liquid shim filling, and peelable fiberglass shim filling were studied. Strain gauges were used in the experiment to measure the strain values in key points around the bolt hole, and the strain field on the surface of specimen was measured using a 3D-DIC strain measurement system. The finite element model was established using ABAQUS to study the damage state of interlaminar layers. This paper analyzes the influence of the gap filling method on the strain and stress state of the composite-aluminum hybrid joint structure and provides a reference for the formulation of the gap filling method.

\section{Problem Description}

Figure 1 shows the basic structure of an aircraft composite wing box. It is composed of an upper panel, a lower panel, a front spar, a rear spar, and three wing ribs. Wherein, the panel and the spar are composite laminate, while the ribs are aluminum alloy. Composite panels were formed using a female mold and deformed after demolding, while the aluminum ribs were machined by $\mathrm{CNC}$, and they had high dimensional accuracy. Therefore, a gap was easily generated between panels and ribs during assembly.

In this paper, the irregular gap was simplified to a uniform gap, as shown in Figure 1. The steel gasket was placed between composite laminate and aluminum plate to create a gap. Three holes were machined on the specimen, and the holes at both ends were used to fix the specimen on the experimental device, while the hole in the middle was used to apply preload of the bolt. This experiment simulated the bolt tightening process of the composite aluminum hybrid bolted structure, and it studied the strain and stress state of composite and aluminum plates with preload. On this basis, the applicable range of various gaps filling method was determined.

\section{Experimental Research}

3.1. Design of Experimental Device and Specimen. The experiment was based on a simplified assembly model, and it simulated the preload by a specially designed experimental device. The experiment included forced assembly and various types of shim filling.

The experimental device was composed of a loading screw, a sliding block, an S-shaped force sensor, a pressing head, and a frame, as shown in Figure 2. The wrenches were used to rotate the loading screws on both sides of the specimen in experiment. The loading screw cannot move because the screw head was against the frame. Then, the sliding block started to slide down. At this time, the rotation of the loading screw was converted into the sliding of the sliding block. The pressing head was indirectly connected to the sliding block by a force sensor. So, the load was measured by force sensor in real time, and the value was displayed via the monitor. When the loading screw pushed the sliding block moving downward, it controlled the sensor and pressing head to move toward the specimen. As the pressing head was in contact with the composite laminate, the change in load can be read by the monitor.

The geometry of the specimen must satisfy the bolted conditions firstly, and the dimensions refer to ASTM D5766/5766 M [38]. The diameter of the bolt shank should be $6.3246 \mathrm{~mm}-6.3373 \mathrm{~mm}(0.2490 \mathrm{in}-0.2495 \mathrm{in})$, while that of the bolt hole was $6.35 \mathrm{~mm}-6.38 \mathrm{~mm}$. The measurement results showed that both the diameter of the bolt shank and bolt hole meet the requirements. The results of nondestructive testing (NDT) showed that no obvious damage was found inside the composite laminate, and no delamination occurred around the hole in composite laminate. The thickness of composite laminate and aluminum plate was $3.76 \mathrm{~mm}$ and $4.00 \mathrm{~mm}$. The strain gauges 1 and 4 measured the tangential strain around the bolt hole, and the strain gauges 2 and 3 measured the radial strain around the bolt hole. The dimensions of the test piece and the arrangement of the strain gauges are shown in Figure 3. The experimental specimens were divided into three types, including a matched group without gap, a forced assembly group with gap, and a 

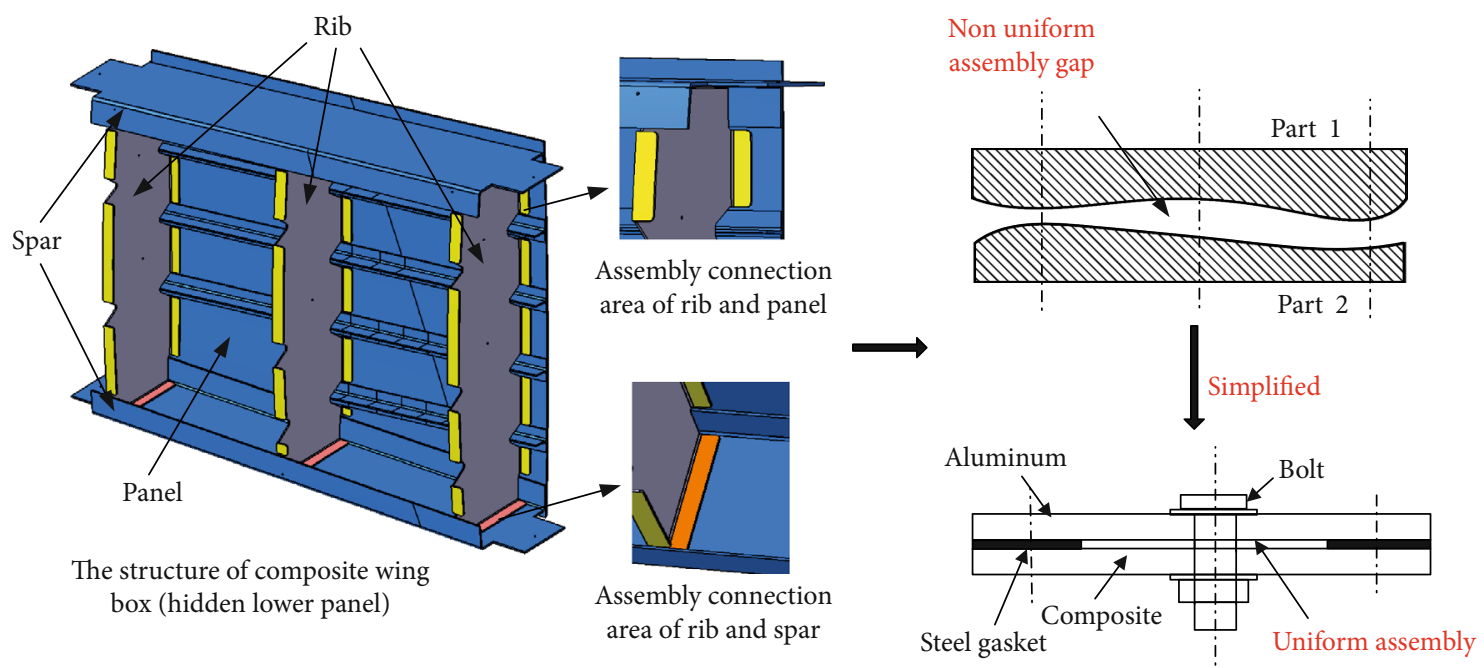

gap

Figure 1: The basic structure of the composite wing box and the establishment of the research model.

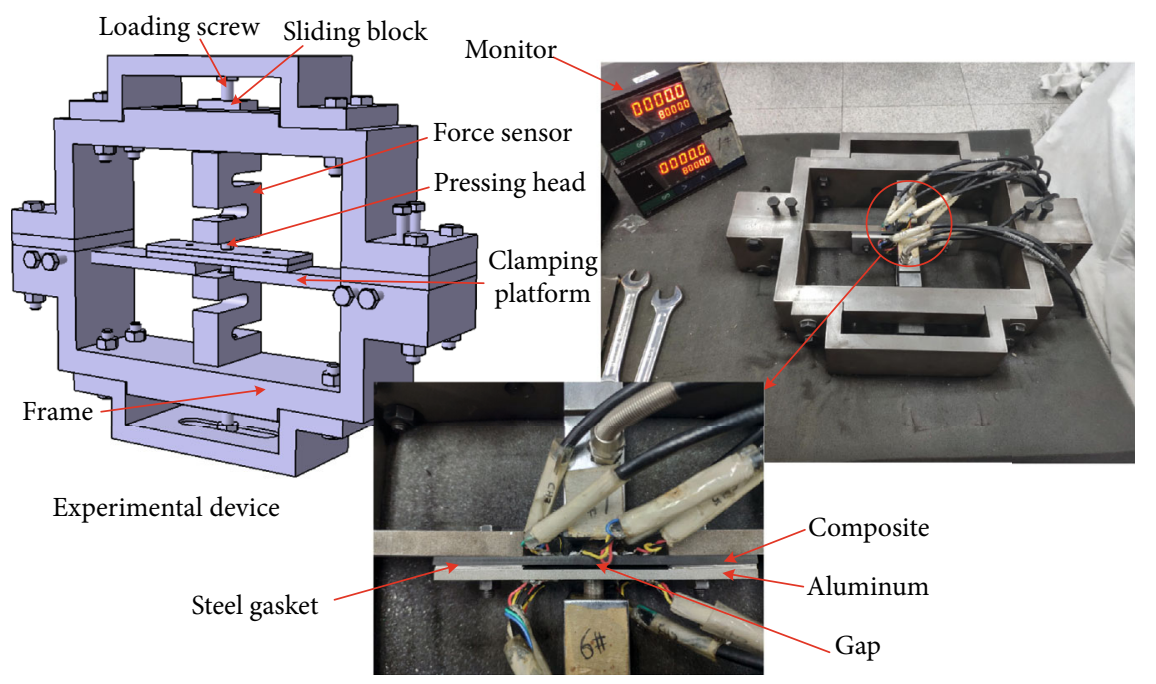

FIgURE 2: Experimental device.

shim-filling group with liquid shim and peelable fiberglass shim. Among them, the gap size and the thickness of various shims was set to $0.2 \mathrm{~mm}-2.0 \mathrm{~mm}$, and the interval was $0.2 \mathrm{~mm}$. Each experimental group was subjected to 5 replicate specimens in the strain gauge measurement experiment.

\subsection{Preparation of Liquid Shim and Peelable Fiberglass Shim.} The liquid shim used in the experiment was the Henkel Loctite Hysol EA9394 two-component structured paste adhesive which cured at room temperature. EA9394 maintains high compressive strength at high temperatures of $180^{\circ} \mathrm{C}$. As the liquid shim was prepared, the mass ratio of the matrix resin to the curing agent is $100: 17[39,40]$. The steel gaskets with a standard thickness were firstly put both ends of the specimen to control the gap thickness before applying liquid shim. The liquid shim was then applied to the surface of composite laminate, and the other side of liquid shim was covered with a plastic film. Finally, the composite laminate was assembled with the aluminum plate to remove excess liquid shim. It can be cured after 168 hours at room temperature. The peelable fiberglass shim was a laminated glass fiber fabric, which was cut according to the gap size in application. Finally, it was adhered to the composite laminate using an adhesive, as shown in Figure 4.

3.3. Strain Gauge Measurement Experiment. The gap was controlled by steel gasket with standard thickness to both ends of the specimen in experiments. The specimen and steel gaskets were connected to the experimental device with bolts. The preload of the bolt used in the experiment was $8 \mathrm{kN}$. During the loading process, a wrench was used to rotate the loading screw counterclockwise, and the load can be recorded in real time through the monitor. After the loading was completed, the strain data was recorded by the strain gauge. Through the above operations, the strain values in four measuring points can be obtained. 

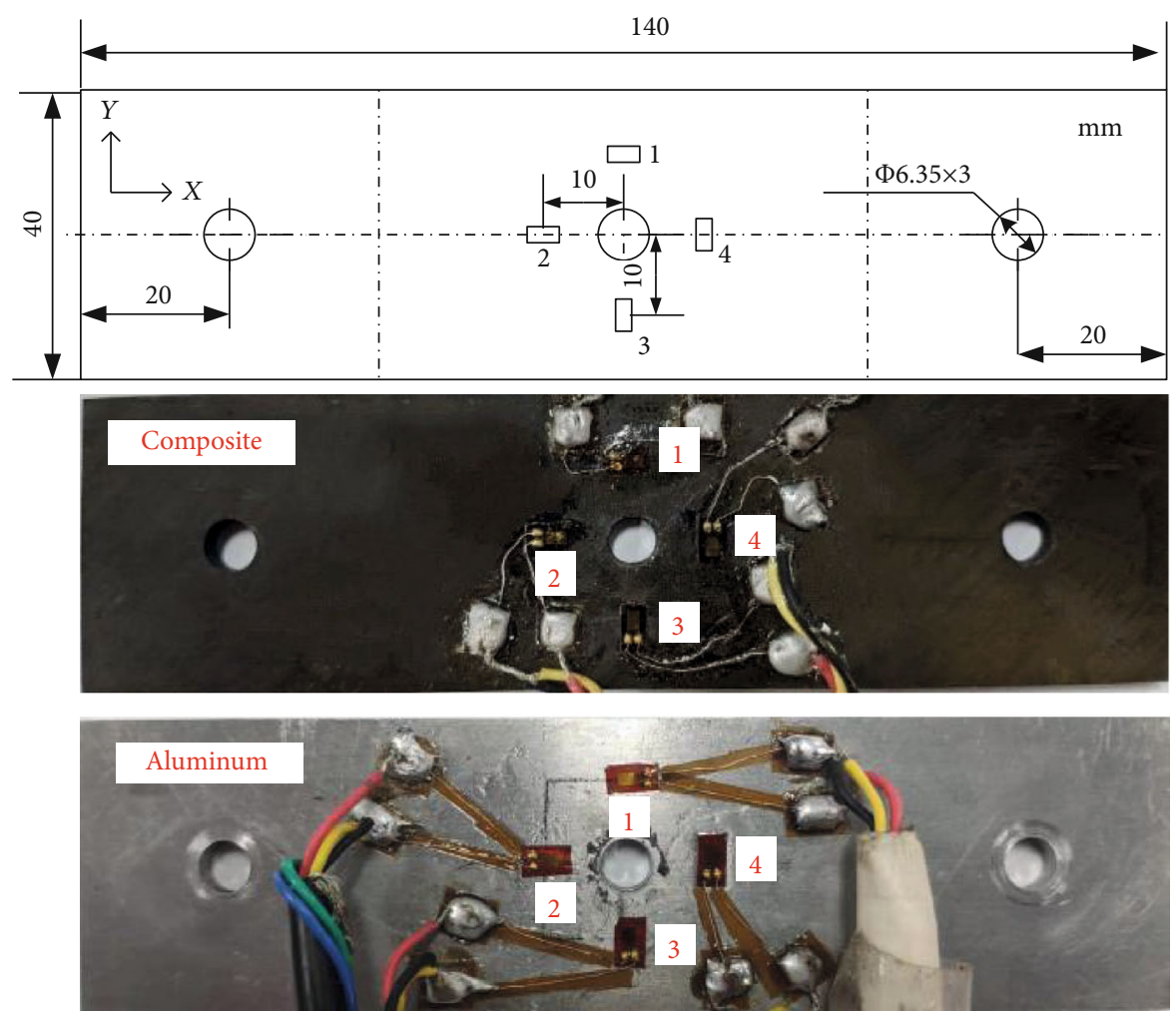

FIgURE 3: Size of specimen and arrangement of strain gauges.

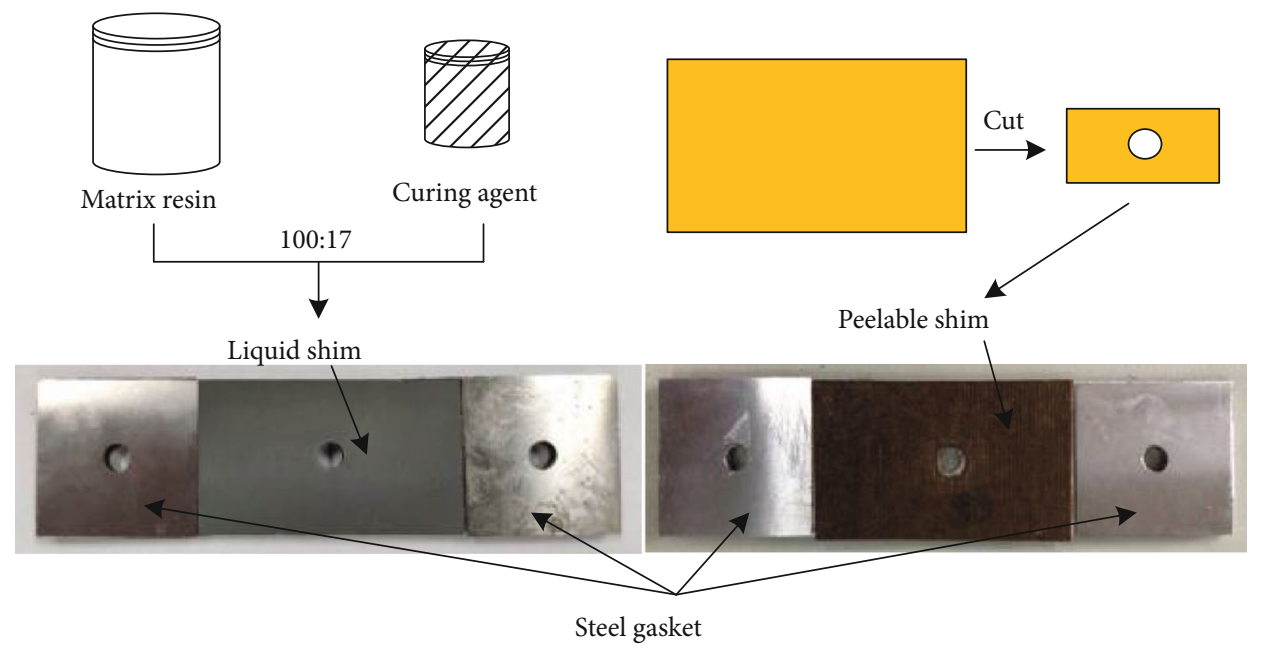

Figure 4: Preparation of liquid shim and peelable fiberglass shim.

3.4. 3D-DIC Measurement Experiment. The 3D-DIC strain measurement system can measure the strain field of the entire outer surface of the component, so this technique is widely used in experimental research $[20,26]$. The 3D-DIC technology is based on the image processing algorithm. By monitoring the change of the speckle pattern on the surface of specimen under load, the displacement and strain of specimen can be obtained, and the deformation rules of each region on the component can be analyzed.

The 3D-DIC system used in the experiment was provided by Correlated Solutions Inc. (CSI). The strain field of the composite laminate and aluminum plate was measured during the application of the bolt preload by the experimental device. The measurement system mainly included two CCD cameras (12 million pixels, frame rate 30 ), two $28 \mathrm{~mm}$ short-focus lenses, a tripod, two light sources, a calibration board, the camera control software, and image processing software. The tripod was mainly used to fix the cameras and adjust the pose of them. The light source was used to increase the brightness of the measured object to obtain a high quality picture. The calibration plate was used to accurately calibrate the camera position so that the optical axes 
of the two cameras intersected at the same point on measured object. The camera control software was used to control the camera to capture images, which can be manually or automatically acquired at a certain frequency. Image processing software was used to calculate the displacement and strain fields of the components under test.

Speckle should be made on the specimen before the experiment. The specimen should be cleaned with acetone to remove dust and grease in the surface firstly. Then, a white matt paint was evenly sprayed on the surface. Finally, a black speckle was made on the specimen using a speckle making tool. According to the size of the measurement field of view and the basic parameters of the camera, the speckle diameter was selected to be $0.33 \mathrm{~mm}$, and the density is $50 \%$, as shown in Figure 5.

The bolt preload was applied to the specimen through the experiment device in the experiment. During this process, the camera was controlled to capture images at a frequency of $1 \mathrm{~Hz}$. After the experiment, the photos were calculated using image processing software to obtain the displacement field and strain field of the specimen. Due to the obstruction of force sensor, only a portion of the area around the bolt hole can be measured using the 3D-DIC measurement system. However, the strain field in this area can reflect the stress distribution around the bolt hole and the deformation of specimen. Based on these experiments, the influence of each gap filling method on the strain and stress of the assembly structure can be analyzed.

\section{Finite Element Analysis}

4.1. Elements, Contact Pairs, and Boundary Conditions. The FEM model was established in ABAQUS/Standard, as shown in Figure 6. In order to simplify the model and improve the calculation efficiency, the bolt, nut, and washer were combined into a whole part in the model. The use of reduced integral elements can avoid the problem of shear self-locking. So, the reduced, linear eight-node, three-dimensional, solid element, C3D8R was used for each component part. The contact area of the bolt and specimen was the stress concentration area. A circle with a radius of $18 \mathrm{~mm}$ was cut around the hole in order to improve the analysis accuracy. The number of seeds in the circle radius was increased, and the local mesh was refined. Each layer of the composite laminate corresponds to one element in the thickness direction.

The bolt shank was in contact with the composite laminate, aluminum plate, and shim in the finite element model. The bolt head and nut were in contact with the upper surface of composite laminate and the lower surface of the aluminum plate, respectively. In the gap filling process, one side of the shim was directly bonded to the component, and the other side was separated from the specimen by a film. Therefore, there was a contact relationship between the shim and the aluminum plate, and the shim was tied with the composite laminate. Bolts and assembly components such as composite laminate, aluminum plate, and shim did not undergo large relative displacements in bolt tightening. So, there was only a small relative sliding between the two contact surfaces. Therefore, the small sliding contact was used to describe

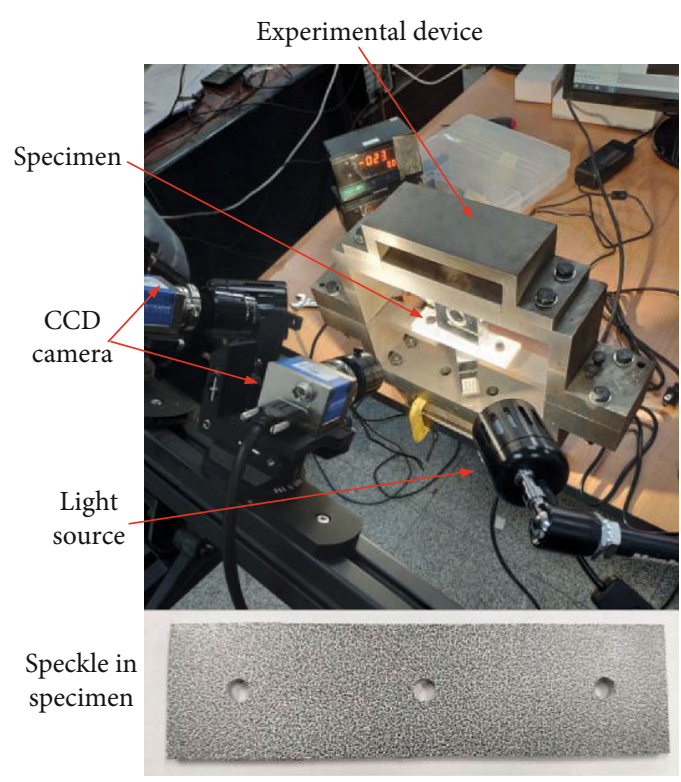

Figure 5: 3D-DIC system to measure the strain field of the specimen.

the relative sliding between contact surfaces. During the whole analysis, the contact and relative sliding between the accessary surface node and the master surface node did not change. So, this model had high computational accuracy. The surfaces in contact with each other in the model were all set as surface-to-surface contact. The penalty friction was used to define the tangential behavior, while the hard contact method was used to define the normal behavior. Friction was considered in each contact area, the metal-to-metal friction coefficient was set to 0.2 , and the rest was set to $0.1[41,42]$.

The load and boundary conditions are shown in Figure 6(c). The bottom surface of the holes at both ends was completely fixed to simulate the installation of specimen on the experimental device. The light springs were used in bolt heads and nuts to constrain their three translational freedoms of $U_{X}, U_{Y}$, and $U_{Z}$. They were also used in two end faces of the composite laminate to constrain the three translational freedoms of $U x, U y$, and $U z$. This setting can guarantee the convergence of the finite element model. A section was provided in the middle of the bolt shank for preload application. In the first analysis step, a preload of $10 \mathrm{~N}$ was applied to the two bolts at the edges to simulate the two ends that are fixed. In the second analysis step, a $10 \mathrm{~N}$ preload was applied to the middle bolt separately. In third analysis step, the middle bolt was applied to a preload of $8 \mathrm{kN}$.

4.2. Material Properties. A carbon fiber epoxy resin composite laminate was used in the study named 977-2. The thickness of a single layer was $0.188 \mathrm{~mm}$, the stacking direction is $\left[45^{\circ} / 90^{\circ} /-45^{\circ} / 0^{\circ} / 90^{\circ} / 0^{\circ} /-45^{\circ} / 90^{\circ} / 45^{\circ} /-45^{\circ}\right]$, and 20 layers were symmetrically stacked. The thickness of laminate was $3.76 \mathrm{~mm}$. Its material properties are shown in Table 1 [43]. The bolt fastener was made of Ti6Al4V, whose Young's modulus is $110 \mathrm{GPa}$ and Poisson's ratio is 0.29 . The aluminum plate was 7050-T7, and its Young's modulus is 72GPa, and 

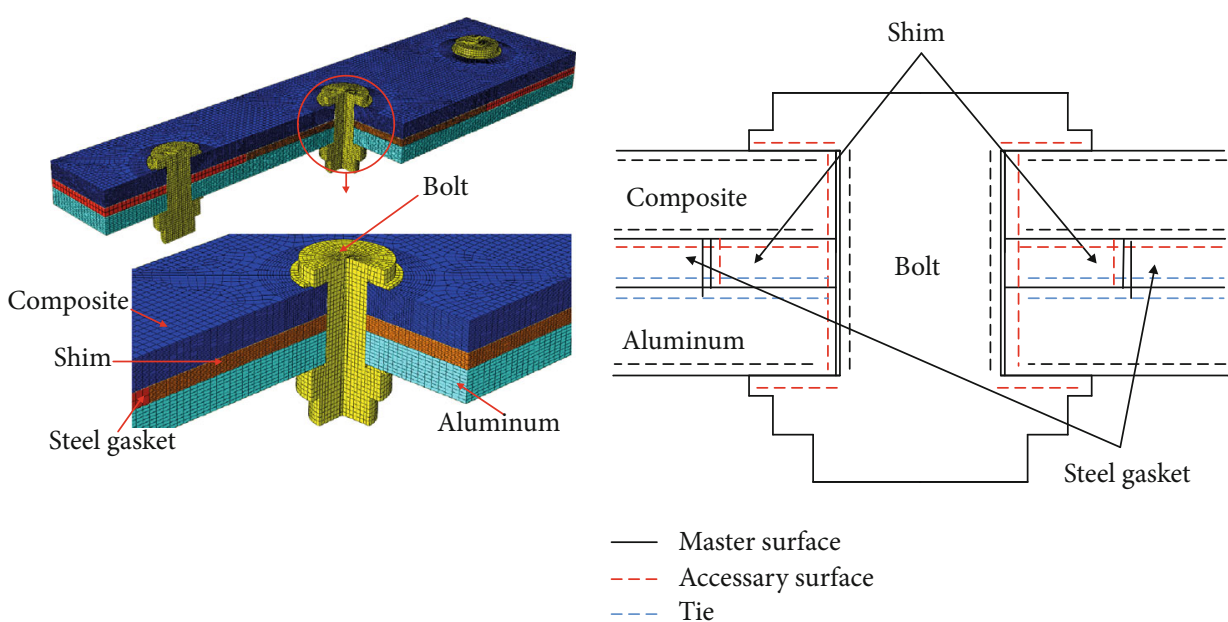

(a)

(b)

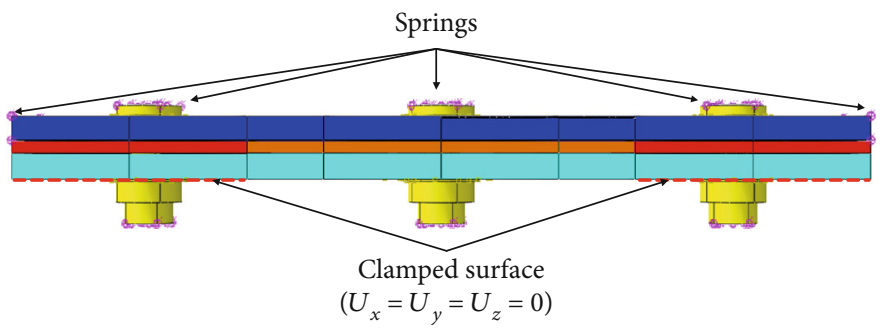

(c)

Figure 6: The finite element model. (a) The mesh of model, (b) The contact pairs in model, and (c) The boundary conditions of model.

Poisson's ratio is 0.33 . The liquid shim is an epoxy material. Its property is between elastic solids and viscous liquids, and the stress and strain show a nonlinear relationship. Liu [23] provided the stress-strain curve of the liquid shim, as shown in Figure 7. The peelable fiberglass shim is glass fiber fabric, and its material properties are similar to composite laminate. The thickness of a single-layer peelable shim was about $0.05 \mathrm{~mm}$, and the layup direction was orthogonal layup at $0^{\circ}$ and $90^{\circ}$. In the specific setting, the number of layers was determined according to different thicknesses. The material parameters are shown in Table 2 [21].

4.3. Setting of Cohesive Zone Elements. The interlaminar strength of composite laminate is lower than that of the intralaminar strength. So, the resistance to delamination of the interlaminar element is relatively poor. The forced assembly can cause significant bending deformation of composite laminate and affect the mechanical properties of the structure. The cohesive zone element is a special element in ABAQUS which is used to simulate the bonding interface. It can be used to investigate the interlaminar stress and damage of composite.

There are many constitutive models describing the stress displacement of cohesive zone elements, including exponential models, polynomial models, trapezoidal models, and bilinear models. Alfano [44] conducted a comprehensive comparative analysis of various cohesive models and found that the form of the bilinear constitutive model was simple. What is more, the accuracy and convergence of this model were excellent. It can be applied to interlaminar elements research of composite laminate. In this paper, the cohesive zone element with a bilinear constitutive model based on the traction-separation criterion in ABAQUS was used.

The relationship of stress $\sigma$ and displacement $\delta$ in the bilinear model is shown in Figure 8. The normal stress $\sigma_{n}$ and two tangential shear stresses $\tau_{s}$ and $\tau_{t}$ were defined as follows:

$$
\left.\begin{array}{l}
\int_{0}^{\delta_{n}^{\max }} \sigma_{n}(\delta) d \delta_{n}=G_{n} \\
\int_{0}^{\delta_{s}^{\max }} \tau_{s}(\delta) d \delta_{s}=G_{s} \\
\int_{0}^{\delta_{t}^{\max }} \tau_{t}(\delta) d \delta_{t}=G_{t}
\end{array}\right\} .
$$

In the formula, $G_{n}, G_{s}$, and $G_{t}$ were the area enclosed by the curve and the abscissa in Figure 8 and represent the critical strain energy release rate. As the displacement was between $0-\delta_{0}$, the interlaminar element was not damaged. And the stress $\sigma$ reached the maximum $\sigma_{\max }$ when the displacement reached $\delta_{0}$. After exceeding this value, the element started to be damaged. And the damage continued to deepen as the displacement increased. The interlaminar element was completely ineffective when the displacement reached $\delta_{r}$. If the thickness of the cohesive zone element was $T_{0}$, then it 
TABLe 1: Composite material properties of 977-2.

\begin{tabular}{lcccccccc}
\hline$E_{11}$ & $E_{22}$ & $E_{33}$ & $G_{12}$ & $G_{13}$ & $G_{23}$ & $v_{12}$ & $v_{13}$ & $v_{23}$ \\
$(\mathrm{GPa})$ & $(\mathrm{GPa})$ & $(\mathrm{GPa})$ & $(\mathrm{GPa})$ & $(\mathrm{GPa})$ & $(\mathrm{GPa})$ & & & \\
\hline 156 & 8.35 & 8.35 & 4.2 & 4.2 & 2.52 & 0.33 & 0.33 & 0.55 \\
\hline
\end{tabular}

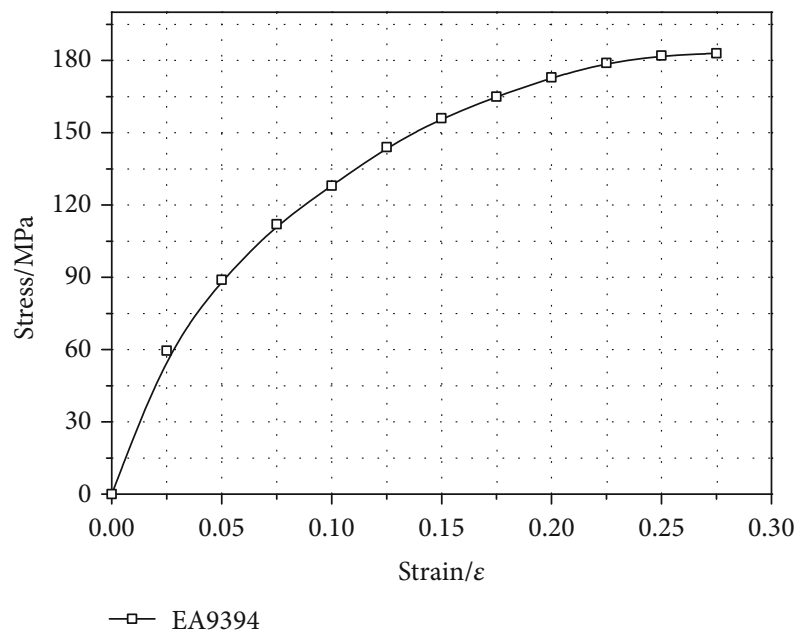

Figure 7: Stress-strain relationship of EA9394.

TABLE 2: Material properties constants of peelable fiberglass shim.

\begin{tabular}{lcccccccc}
\hline$E_{11}$ & $E_{22}$ & $E_{33}$ & $G_{12}$ & $G_{13}$ & $G_{23}$ & $v_{12}$ & $v_{13}$ & $v_{23}$ \\
$(\mathrm{GPa})$ & $(\mathrm{GPa})$ & $(\mathrm{GPa})$ & $(\mathrm{GPa})$ & $(\mathrm{GPa})$ & $(\mathrm{GPa})$ & & \\
\hline 20.1 & 20.1 & 8.1 & 3.3 & 3.3 & 3.3 & 0.18 & 0.18 & 0.18 \\
\hline
\end{tabular}

was divided by the initial thickness of the cohesive zone element in all directions and obtained the strain value:

$$
\varepsilon_{n}=\frac{\delta_{n}}{T_{0}}, \varepsilon_{s}=\frac{\delta_{s}}{T_{0}}, \varepsilon_{t}=\frac{\delta_{t}}{T_{0}} .
$$

When $\delta<\delta_{0}$, it was the phase of linear elasticity.

$$
\left\{\begin{array}{c}
\sigma_{n} \\
\tau_{s} \\
\tau_{t}
\end{array}\right\}=\left[\begin{array}{lll}
k_{n n} & \\
& k_{s s} & \\
& & k_{t t}
\end{array}\right]\left\{\begin{array}{l}
\varepsilon_{n} \\
\varepsilon_{s} \\
\varepsilon_{t}
\end{array}\right\}=\left[\begin{array}{lll}
k_{n n} & \\
& k_{s s} & \\
& & k_{t t}
\end{array}\right]\left\{\begin{array}{l}
\frac{\delta_{n}}{T_{0}} \\
\frac{\delta_{s}}{T_{0}} \\
\frac{\delta_{t}}{T_{0}}
\end{array}\right\} .
$$

When $\delta<\delta_{0}, \sigma$ reached the maximum $\sigma_{\max }$. The secondary stress criterion was used as the damage onset criterion of the element [45]. The criterion is

$$
\left(\frac{\left\langle\sigma_{n}\right\rangle}{\sigma_{n}^{\max }}\right)^{2}+\left(\frac{\tau_{s}}{\tau_{s}^{\max }}\right)^{2}+\left(\frac{\tau_{t}}{\tau_{t}^{\max }}\right)^{2}=1
$$

When $\delta>\delta_{0}$, the cohesive element was damaged, and the damage continued to expand as the displacement increased. The evolution of the damage was judged based on the power law:

$$
\left(\frac{G_{n}}{G_{n}^{c}}\right)^{\alpha}+\left(\frac{G_{s}}{G_{s}^{c}}\right)^{\alpha}+\left(\frac{G_{t}}{G_{t}^{c}}\right)^{\alpha}=1
$$

$G_{n}^{c}, G_{s}^{c}$, and $G_{t}^{c}$ were critical fracture toughness.

In order to study the damage between layers of the composite laminate, a layer of the cohesive zone element was added between layer 1 and layer 2 on the upper surface of the composite laminate, as shown in Figure 9. The type of the cohesion element was COH3D8, and the mechanical properties are shown in Table 3 [46].

4.4. Mesh Sensitivity Analysis. The mesh sensitivity analysis was performed firstly as the FEM model was built. In order to obtain more accurate calculation results, the mesh density of the area around the hole in composite laminate was greater than that of other areas. Therefore, the radial size of the elements in this area was selected to analyze the mesh sensitivity. The radial size of the element was set to $0.1 \mathrm{~mm}-1.0 \mathrm{~mm}$, and the strain value in the $X$-direction of the element integration point around point 1 was extracted. Then, the difference between the finite element results and the experimental values was analyzed. In addition, the computation time (with $4 \mathrm{CPU}$ processors computer) of each model was compared. The analysis result is shown in Figure 10. Considering the simulation accuracy and computation time, the final radial size of the selected element was $0.35 \mathrm{~mm}$.

\section{Results and Discussion}

5.1. Model Verification. There were two kinds of experiments designed in the research, including strain gauge measurement experiments and 3D-DIC measurement experiments. The purpose of the strain gauge measurement experiment was to study the changes of strain in $X$ - and $Y$-directions around the hole under preload of the bolt and to analyze the influence of gap and shims on strain and deformation of specimen. The purpose of the 3D-DIC measurement experiment was to study the strain field distribution characteristics around the hole. Due to the obstruction of force sensor, only a part of the specimen can be measured during the experiment. However, with the results from strain gauges experiments, the analysis of the measurement area can be used to study the strain distribution and deformation of the component. In the finite element model, the cohesive zone element was used at the interface between the layers. On this basis, the interlaminar stress and damage of the composite laminate near the bolt head can be studied. Experimental research and finite element simulation were used to analyze the influence of gap and shims on the strain and stress of composite-aluminum assembly structures in multiple angles.

The experimental group with a gap of $2.0 \mathrm{~mm}$ was selected to compare the results from strain gauge measurement experiments, 3D-DIC measurement experiments, and finite element simulations, as shown in Figure 11. The measuring point 1 measured the strain in the $X$-direction around 


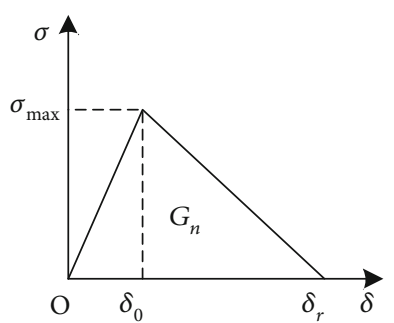

(a) Normal tension-displacement relationship

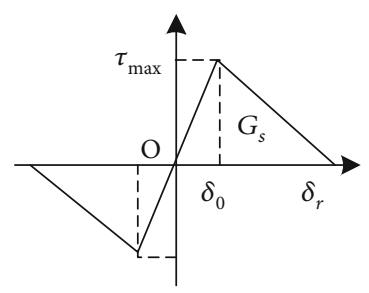

(b) Tangential tension-displacement relationship

Figure 8: Bilinear model of the cohesive element.

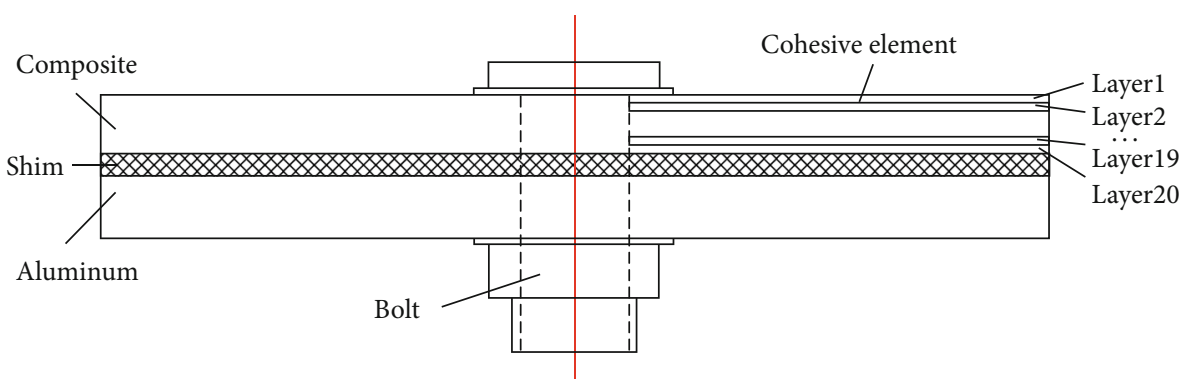

FIGURE 9: Schematic diagram of the cohesion element.

TABLE 3: Mechanical properties of the cohesive element.

\begin{tabular}{|c|c|c|c|}
\hline Property & Value & Property & Value \\
\hline Normal stiffness, $K_{n}\left(\mathrm{~N} / \mathrm{mm}^{3}\right)$ & $1 \times 10^{5}$ & Interlaminar strength, $t_{n}(\mathrm{MPa})$ & 60 \\
\hline Tangential stiffness, $K_{s}\left(\mathrm{~N} / \mathrm{mm}^{3}\right)$ & $1 \times 10^{5}$ & Interlaminar strength, $t_{s}(\mathrm{MPa})$ & 80 \\
\hline Tangential stiffness, $K_{t}\left(\mathrm{~N} / \mathrm{mm}^{3}\right)$ & $1 \times 10^{5}$ & Interlaminar strength, $t_{t}(\mathrm{MPa})$ & 80 \\
\hline Critical fracture toughness, $G_{n}^{c}(\mathrm{~N} / \mathrm{mm})$ & 0.352 & Density, $\rho\left(\mathrm{g} / \mathrm{mm}^{3}\right)$ & $2 \times 10^{-9}$ \\
\hline Critical fracture toughness, $G_{s}^{c}(\mathrm{~N} / \mathrm{mm})$ & 1.45 & Viscosity coefficient, $\mu$ & $1 \times 10^{-5}$ \\
\hline Critical fracture toughness, $G_{t}^{c}(\mathrm{~N} / \mathrm{mm})$ & 1.45 & & \\
\hline
\end{tabular}

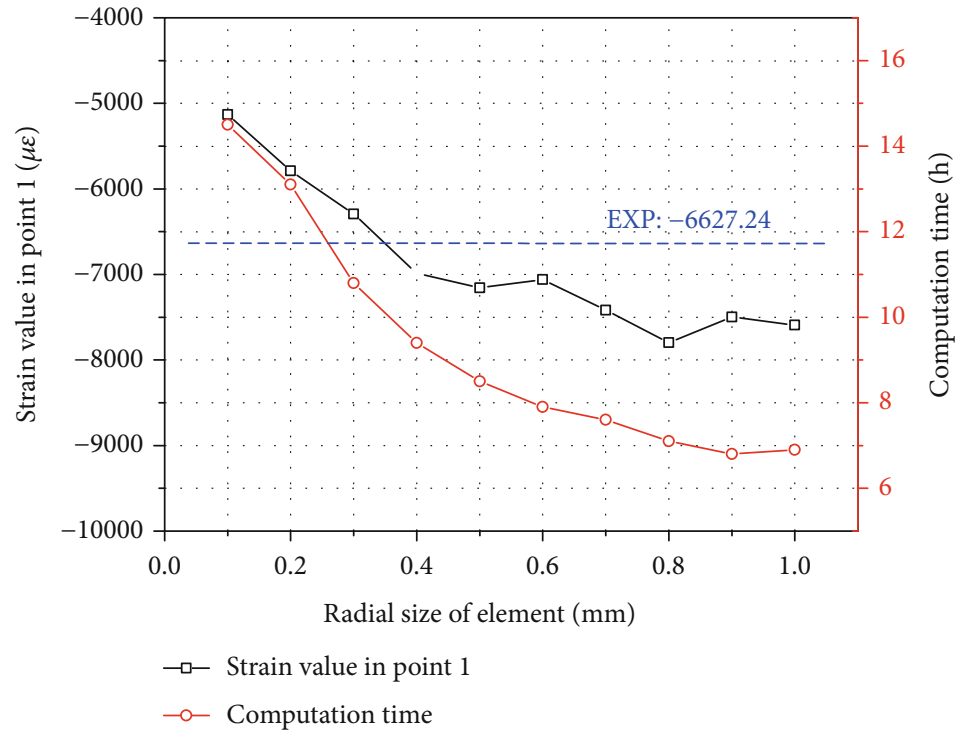

FIGURE 10: The mesh sensitivity analysis of element in composite laminate (specimen with gap $2.0 \mathrm{~mm}$ ). 


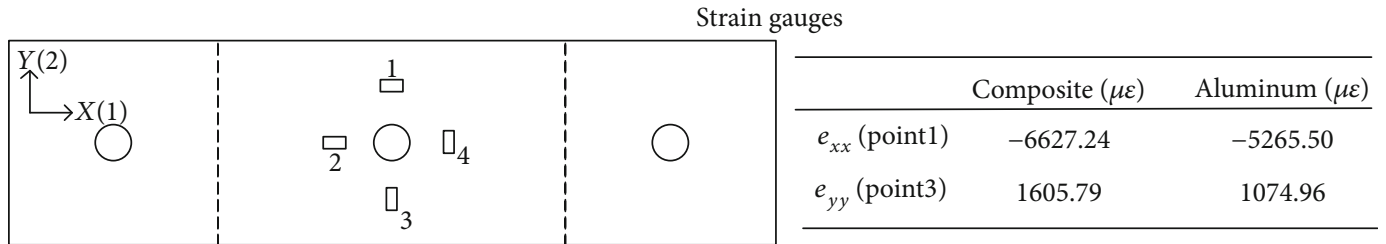

(a)
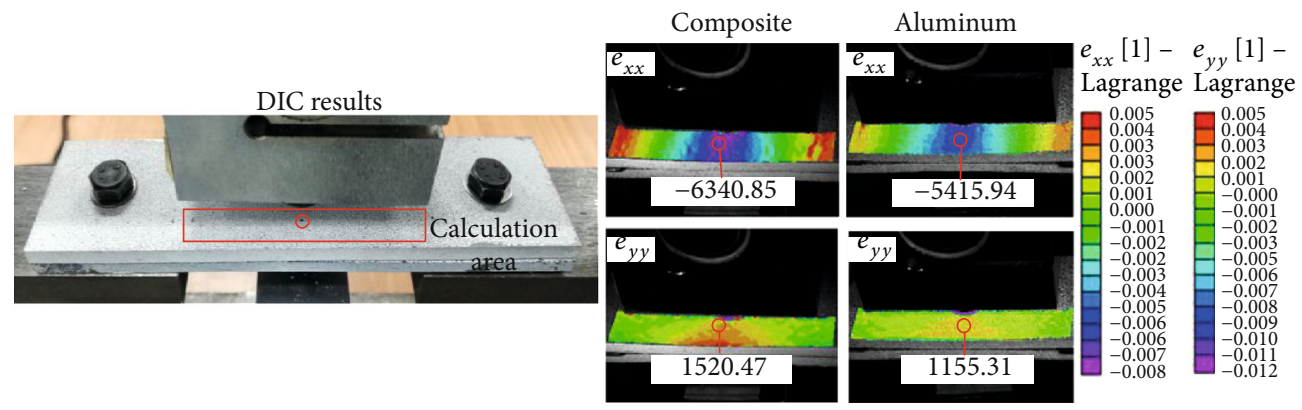

(b)

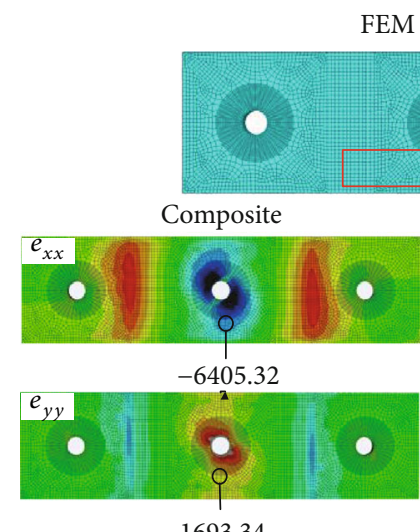

EM results

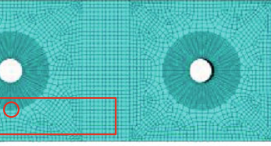

E, E11

Mid, $($ fraction $=0.0)$ Mid, $($ fraction $=0.0)$

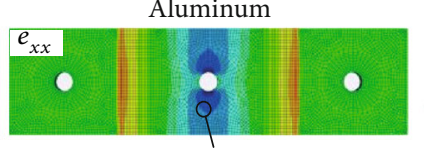

(Avg. $75 \%$ )

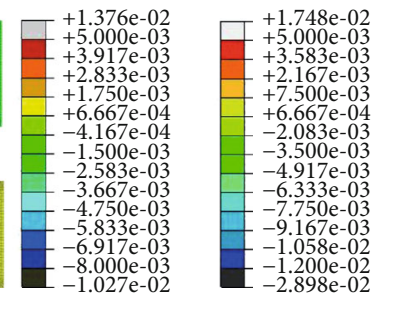

(c)
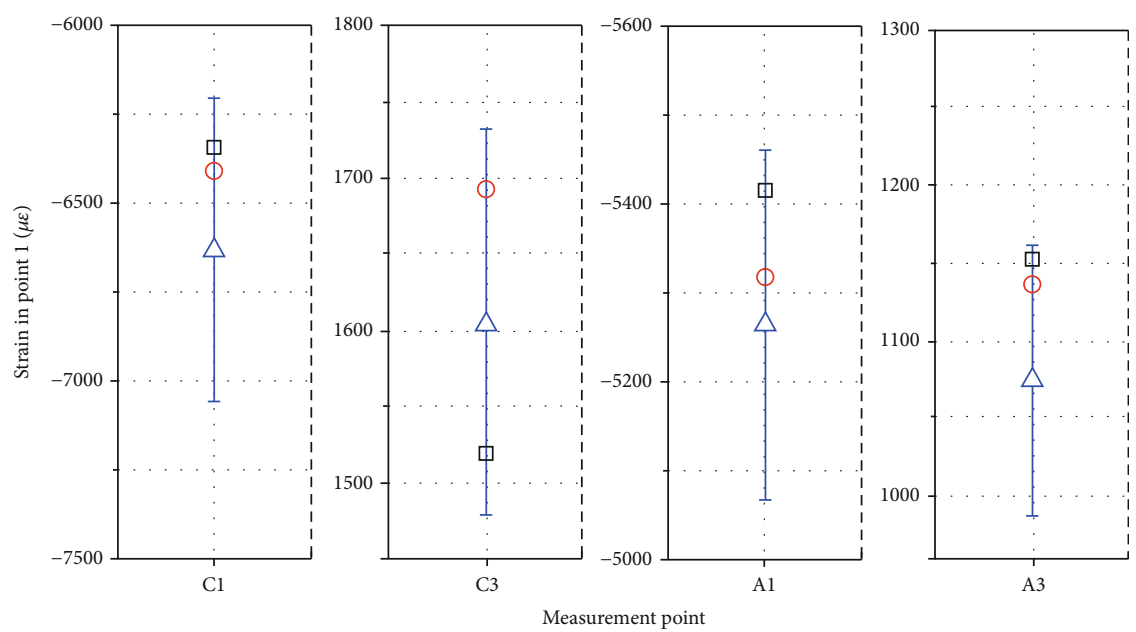

$\square$ DIC

O FEM

$\triangle$ Strain gauge

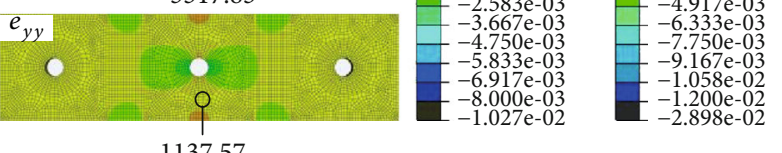




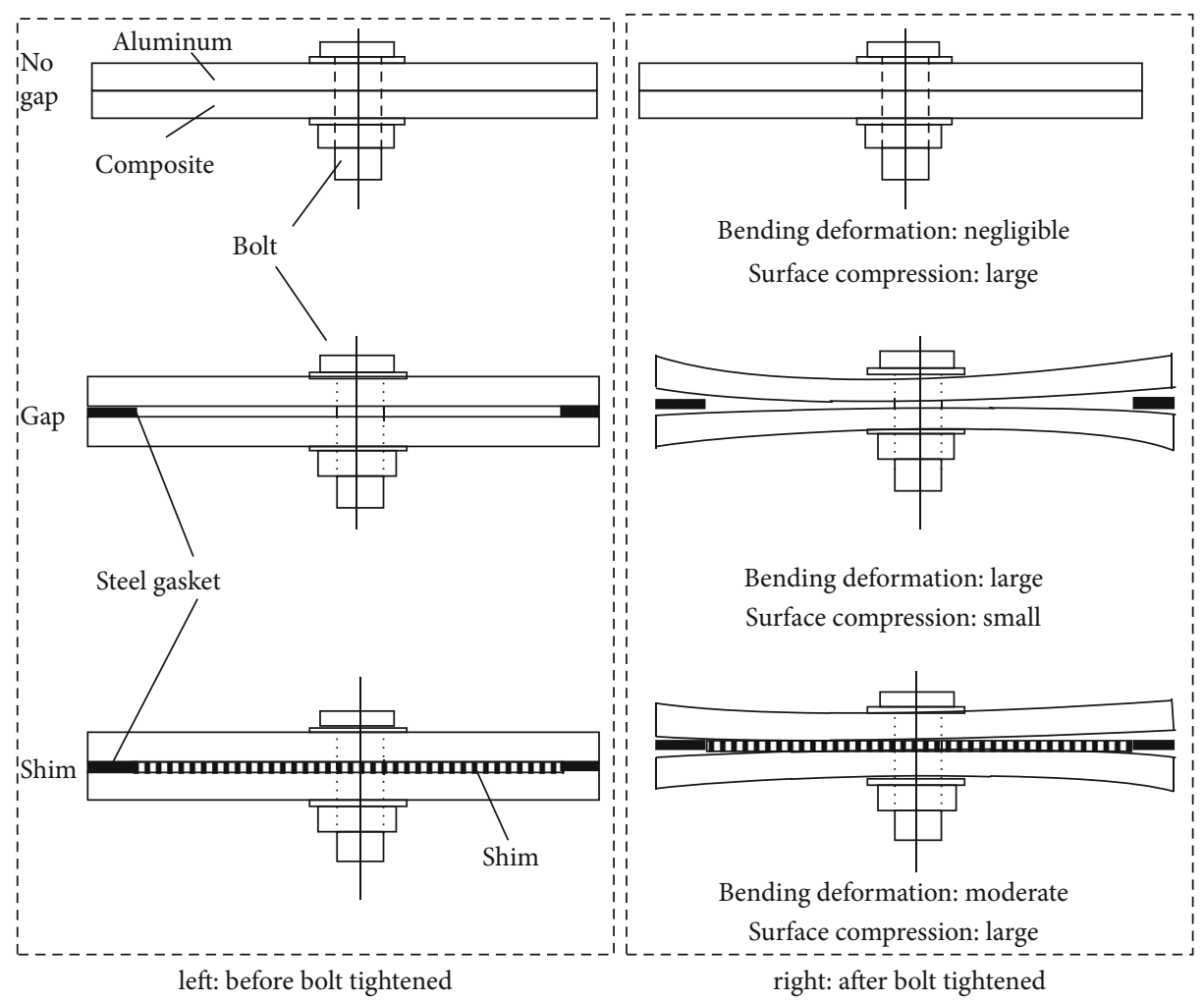

FIgURE 12: Deformation of the specimens under the preload.
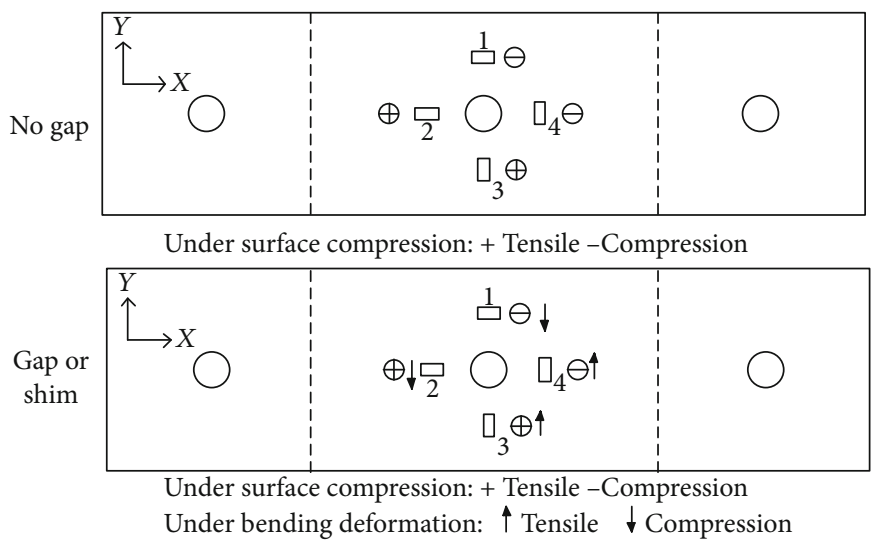

FIGURE 13: Strain properties of various measurement points around the hole under preload.

the hole, and the measuring point 3 measured the strain in the $Y$-direction. Figure 11(a) shows the average results of strain in the strain gauge measurement experiment. Figure 11(b) shows the strain value measured by $3 \mathrm{D}$-DIC. Figure 11(c) shows the strain values in element integration points around measuring points 1 and 3 in finite element results. Figure $11(\mathrm{~d})$ shows the comparison of the strain values measured by the three methods, in which the average value and standard deviation of 5 replicate specimens in strain gauge measurement experiments were considered. It can be found that the results obtained from the 3D-DIC experiment and finite element model were within the deviation range of the results obtained from the strain gauge mea- surement experiment. Therefore, it can be determined that the results obtained by the three methods were credible.

\subsection{Strain Analysis}

5.2.1. Strain State without Assembly Gap. Figure 12 shows the deformation of the assembly structure under the preload. Figure 13 shows the properties of strain at each measuring point of the composite-aluminum connection structure under the action of the surface compression in the bolt head and bending deformation of specimen. Among them, the specimen without gap only considered the compression of the bolt head and did not consider the bending of specimen. 
In the specimens with gap and shims, these two factors need to be considered together. Figure 14 shows the variation of the strain value with different gaps and shims. Since each experimental group in the strain gage measurement experiment requires 5 replicate samples, Figure 14 contains the average value and standard deviation of each group of experiments. Various errors in the experiment can cause differences between measurement results. These errors include molding defects and dimensional deviations of composite laminates, shim size deviations, and the errors of sensor. It can be seen from results that the standard deviation of each experimental group was relatively small, and the consistency of results was great. Therefore, the results can be used to analyze the change behavior of the strain value in each measuring point. The experimental results show that compression of the bolt head can cause serious deformation on the surface of specimen. This phenomenon affects the surface strain distribution of the component, as shown in Figure 13. In both composite laminate and aluminum plate, the strain values at measurement points 1 and 4 are negative while the strain values at measurement points 2 and 3 are positive. The measuring points 1 and 4 are distributed along the circumferential direction of the bolt hole, and the measuring points 2 and 3 are distributed along the bolt hole radius. Under the action of preload, the material around the bolt hole is greatly deformed due to compression. The radial direction of the bolt hole is in a tensile state so the strain value is positive, such as measuring points 2 and 3 , while the circumferential direction of the hole is in a compressed state so the strain value is negative, such as measuring points 1 and 4 .

5.2.2. Strain State in Forced Assembly. Under the preload of bolt, the composite-aluminum assembly structures undergo bending deformation due to existence of assembly gap, as shown in Figure 12. Bending deformation causes compressive strain in the measuring points 1 and 2 while it causes tensile strain in the measuring points 3 and 4 . Therefore, the bending deformation generated under forced assembly can make the strain values at measurement points 1 and 2 to be negative and the strain values at 3 and 4 to be positive. The bending deformation of the component increases with the gap, at the same time the strain value at each measuring point gradually increases.

It can be seen from Figure 14 that measuring points 1 and 3 have the same strain change tendency under preload and bending deformation of specimens while that of measuring point 2 and 4 are different. In the case of preload compression, the measuring point 2 is in tensile state and the strain is positive. In the case of bending deformation, it is in compressed state and the strain is negative. The trend of measurement point 2 in Figure 14 is negative so it can be concluded that the influence of the bending deformation of the component is greater than that of the surface compression in the measuring point 2 . The strain caused by bending deformation plays a major role in $\mathrm{X}$-direction of specimen. Contrary to measuring point 2 , measuring point 4 has a negative strain under preload compression. While it is in a tensile state and has a positive strain in bending deformation. In Figure 14, the strain value at test point 4 is negative, and the strain value increases with the gap. So it can be concluded that the strain caused by preload compression is greater than the strain caused by bending of the specimen at test point 4 . In the $\mathrm{Y}$-direction of the specimen, preload compression plays a major role.

\subsubsection{Strain State of Specimens with Liquid Shim and Peelable} Fiberglass Shim. In case of adding liquid shim or peelable fiberglass shim to assembly gap, the curve of the strain at each measuring point is shown in Figure 14. For measuring point 1 , the strain is greatly reduced after the shim filling compared with forced assembly. In the gap of $0.2 \mathrm{~mm}$, the strain of composite laminate with liquid shim and peelable fiberglass shim filling is reduced by $13.38 \%$ and $8.31 \%$, respectively, and that of the aluminum plate is reduced by $50.68 \%$ and $36.44 \%$, respectively. In the gap of $2.0 \mathrm{~mm}$, the strain of the composite laminate with liquid shim and peelable fiberglass shim is reduced by $70.97 \%$ and $64.03 \%$, respectively, and that of the aluminum plate is reduced by $70.25 \%$ and $63.54 \%$, respectively. The addition of the shim greatly reduces the strain caused by the bending deformation of the composite laminate and the aluminum plate. The reduction of the strain value increases with shim thickness. Comparing the effect of liquid shim and peelable fiberglass shim, it can be seen that the strain value is lower when using the liquid shim. Therefore, the liquid shim has achieved a better filling effect than peelable fiberglass shim in measuring point 1 .

Analysis of measuring point 2 shows that the area around measuring point 2 is mainly affected by preload compression around the hole without assembly gap, and the strain value is positive. Due to bending deformation of the specimen, the strain value of measuring point 2 changes from positive to negative with assembly gap. After the shim is filled, the strain value at each measuring point is also greatly reduced due to reduced bending deformation, which is in positive values. When the gap is $0.2 \mathrm{~mm}$, the strain of the composite laminate with the liquid shim and the peelable fiberglass shim filling is little increased by $8.93 \%$ and $29.44 \%$, respectively, and the corresponding aluminum plate is reduced by $40.41 \%$ and $35.84 \%$, respectively. When the gap is $2.0 \mathrm{~mm}$, the strain of the composite laminate with the liquid shim and the peelable fiberglass shim filling is reduced by $44.23 \%$ and $21.20 \%$, respectively, and the corresponding aluminum plate is reduced by $78.17 \%$ and $76.28 \%$, respectively. When the liquid shim is used, the strain value of each measurement point is slightly lower than using peelable fiberglass shim. So, a better effect can be obtained with liquid shim in measuring point 2 .

The strain value of measuring point 3 is positive when the gap is $0 \mathrm{~mm}$. Due to the bending deformation of the specimen, the area near the measuring point 3 is still affected by the tensile strain, and the strain value increases with the gap. There are some differences in the influence of shims on composite laminate and aluminum plates in gap filling. By analyzing the strain of composite laminate, it can be seen that when the thickness of the liquid shim is in the range of $0.2 \mathrm{~mm}-1.0 \mathrm{~mm}$, the strain value at the measurement point 3 is higher than that in forced assembly. When the thickness of the liquid shim is within the range of $1.2 \mathrm{~mm}-2.0 \mathrm{~mm}$, the strain value at is lower than that of the forced assembly. As 

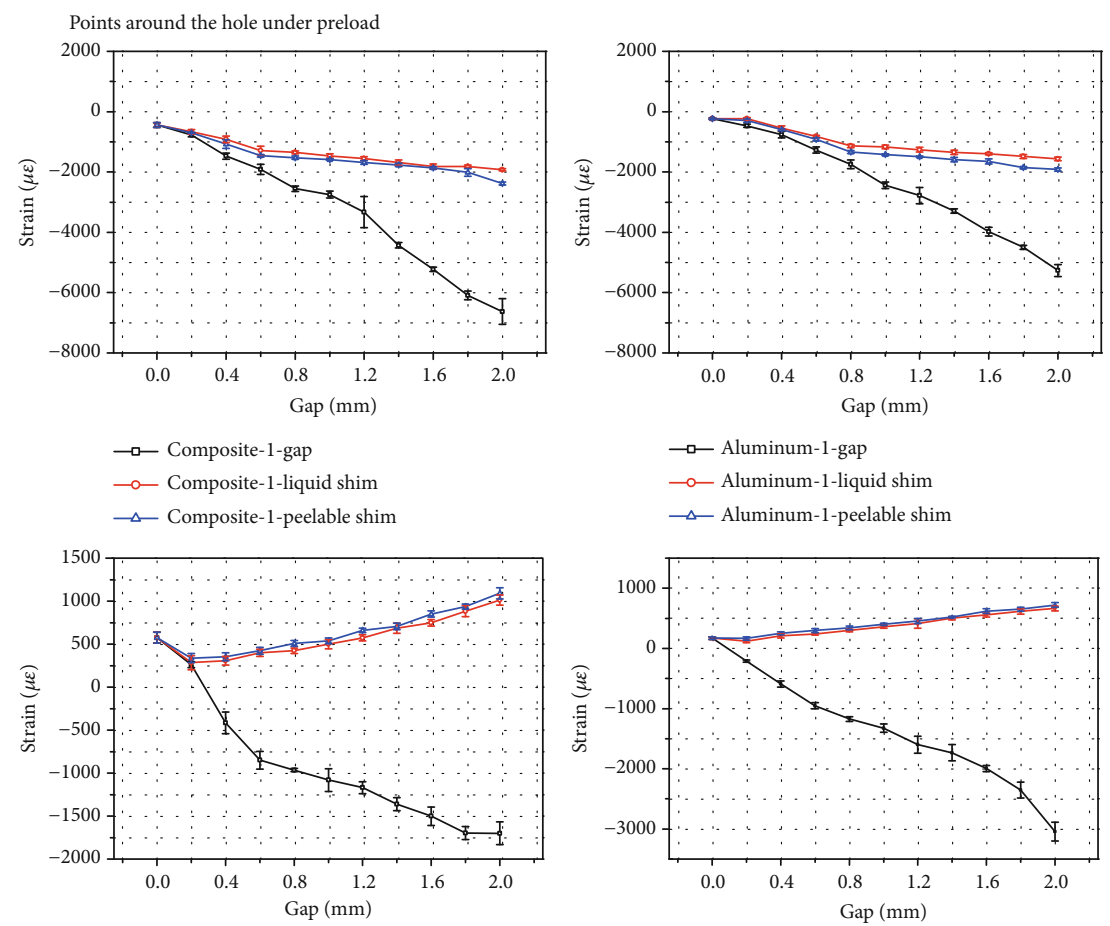

$$
\begin{aligned}
& \rightarrow-\text { Composite-2-gap } \\
& \multimap-\text { Composite-2-liquid shim }
\end{aligned}
$$

$\neg-$ Composite-2-peelable shim

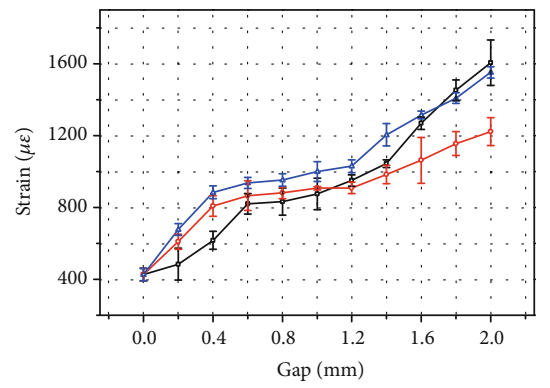

$\multimap$ Aluminum-2-gap

$\ldots$ Aluminum-2-liquid shim

$\triangle$ Aluminum-2-peelable shim

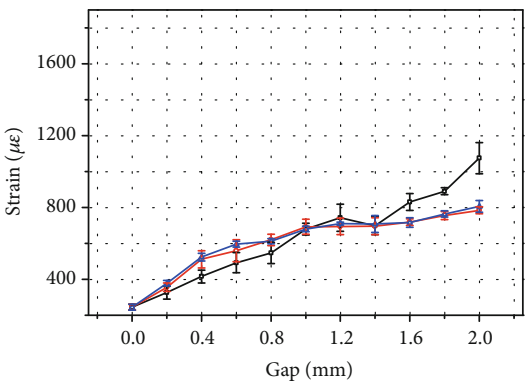

$\longrightarrow$ Composite-3-gap

$\multimap-$ Composite-3-liquid shim

$\neg$ Composite-3-peelable shim

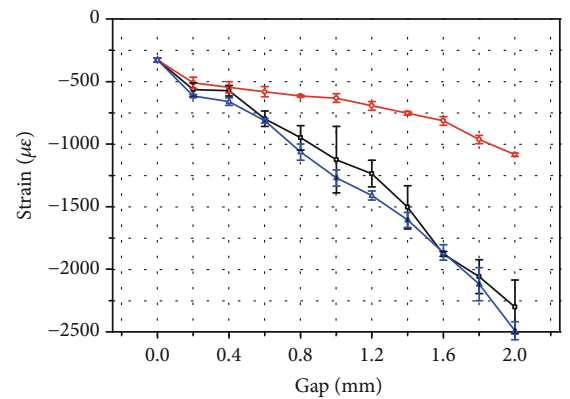

$\rightarrow$ Aluminum-3-gap

$\multimap-$ Aluminum-3-liquid shim

$\neg-$ Aluminum-3-peelable shim

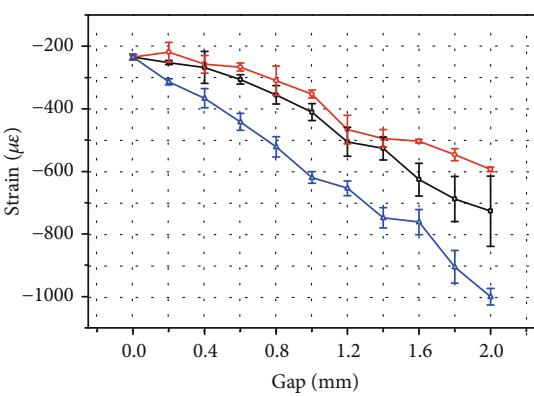

- - Composite-4-gap

$\multimap$ Composite-4-liquid shim

๑-Aluminum-4-gap

- - Aluminum-4-liquid shim

$\triangle \_$Aluminum-4-peelable shim

FIGURE 14: Variations of strain values at measuring points with gap and shim thickness.

the thickness of shim is $1.2 \mathrm{~mm}$, the strain value can be reduced by $4.41 \%$, and it can be reduced by $23.93 \%$ in liquid shim thickness of $2.0 \mathrm{~mm}$. The effect of liquid shim filling can be better with larger gap. As peelable fiberglass shim is used, the strain value in the range of $0.2 \mathrm{~mm}-1.6 \mathrm{~mm}$ is greater than that in forced assembly, and only in the range of $1.8 \mathrm{~mm}$ $2.0 \mathrm{~mm}$ is slightly lower than the strain value in forced assembly. It can be seen that the peelable fiberglass shim can hardly 


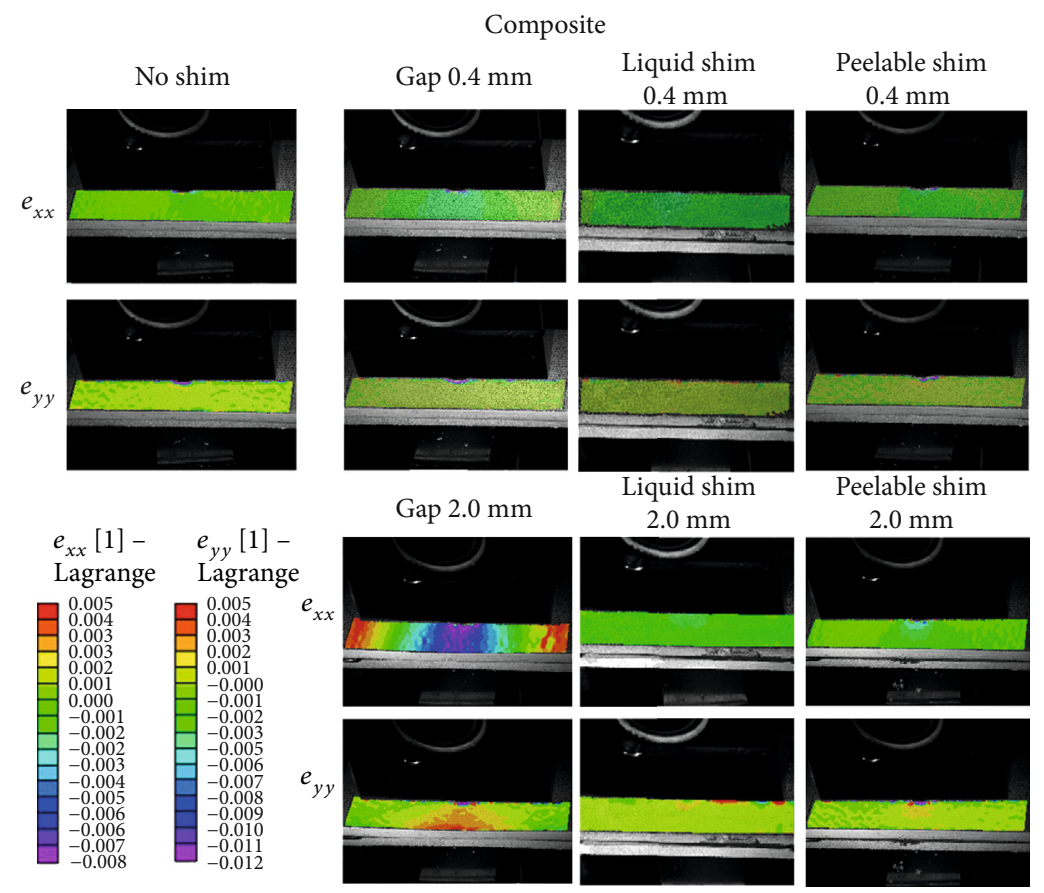

FIGURE 15: Surface strain field of composite laminates in different experimental groups.

reduce the strain value in the area near the measurement point 3 in composite laminate, and the liquid shim can reduce the strain value only in the range of $1.2 \mathrm{~mm}-2.0 \mathrm{~mm}$. Analysis of the strain in aluminum plate shows that when the gap is in the range of $0.2 \mathrm{~mm}-1.0 \mathrm{~mm}$, the shim filling leads to increase in the strain value. In the range of $1.2 \mathrm{~mm}-$ $2.0 \mathrm{~mm}$, the shim filling reduces the strain value of the measurement point 3. Among them, the strain value decreases by $6.43 \%$ when the thickness of the shim is $1.2 \mathrm{~mm}$ and decreases by $27.02 \%$ when shim is $2.0 \mathrm{~mm}$.

Analysis of measuring point 4 shows that the strain value is negative when there is no gap. The bending deformation of the specimen generates a positive strain at the measuring point 4 with assembly gap. However, since the compression effect of the bolt at this position is dominant, the strain value at measuring point 4 is still negative, and it increases with the increase of the gap. After filling the liquid shim, the strain value at measuring point 4 decreases. At a gap of $0.2 \mathrm{~mm}$, the strain value of the aluminum plate is reduced by $13.08 \%$ after the liquid shim filling, and that of composite laminate is reduced by $9.53 \%$. However, after filling the peelable fiberglass shim, the strain value of each measuring point almost increases, and the effect of reducing the strain value is not achieved.

Figures 15 and 16 show the strain field on the surface of composite laminate and aluminum plate, respectively. It can be seen from the figures that the specimen has obvious bending deformation in forced assembly. In the $X$-direction, both ends of specimen are in tensile strain since there are bolts to fix the specimen. Due to bending deformation of specimen and preload of bolt, the middle part of specimen is in compressive strain. In the $Y$-direction, the specimen has compressive strain at both ends and tensile strain in the middle part. Shims reduce the bending deformation of specimen, and they can reduce the strain value in most areas of the specimen surface. Therefore, the strain distribution on the surface of specimen is more uniform, which improves the assembly stress distribution of the structure.

By analyzing the strain values at the above four measuring points, it can be seen that shims can significantly reduce the bending deformation of the specimen. The bending deformation mainly affects the strain value in the $X$-direction. Therefore, the strain value of the measurement points 1 and point 2 is greatly reduced with the shim filling. The stiffness of peelable fiberglass shim in the thickness direction is greater than that of the liquid shim. Therefore, the bending deformation of the specimen is small using peelable fiberglass shim. At the same time, the surface compression effect is more serious. As the shims are used, the strain state in the area around each measurement point is similar to the case without gap. The strain value of each measuring point is mainly affected by the compression of the bolt head, so the strain value of the peelable fiberglass shim filling is greater than that of the liquid shim filling.

During forced assembly, the specimen is less affected by bending deformation in the $Y$-direction, and it is more affected by the compression of the bolt head. Although the shim filling can reduce the bending deformation of the specimen, it cannot guarantee that the strain values of the measurement points 3 and 4 are smaller than that of forced assembly in all cases. Under the residual bending deformation and severe bolt compression, the phenomena that a strain value larger than that of forced assembly can appear with peelable fiberglass shim. The stiffness of liquid shim in the thickness direction is small, which weakens the compression effect to a certain extent. Therefore, in most cases, the strain at 3 and 4 measuring points can be reduced with liquid shim. 


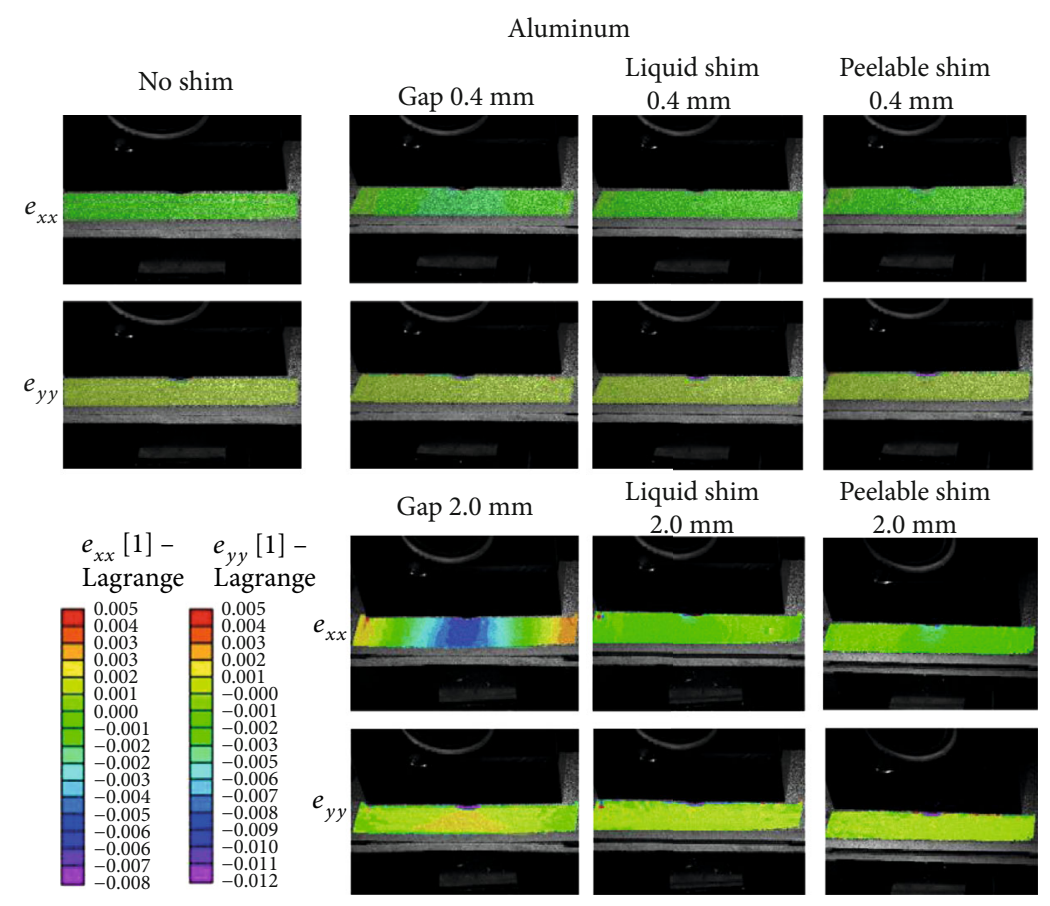

FIGURE 16: Surface strain field of aluminum plates in different experimental groups.

By analyzing the experimental results, it can be seen that as shim increases, the magnitude of its reduction in the strain value also increases, and the effect of gap filling is more obvious. Liquid shim filling can reduce the strain values in measuring points in most cases. The peelable fiberglass shim has a reducing effect on the strain value in the $X$-direction of the specimen, but in most cases, it causes an increasing strain value in the $Y$-direction. Since the thickness of the aluminum plate is larger than that of the composite laminate, the stiffness of the aluminum plate is greater than that of the composite laminate in the experiment. The strain value of each measurement point in the aluminum plate is smaller than that in the composite laminate. However, the change behavior of the strain values at each measuring point is similar in these two plates.

5.3. Stress Analysis. The composite laminate is compressed by the bolt head as assembled structures is tightened, resulting in localized stress concentration. Local damage in interlaminar element may occur during the tightening process with a gap or unreasonable gap filling method. It was found that the surface of the composite laminate may be damaged when the assembly gap is too large. The area where the bolt head pressed is prone to have delamination damage. Therefore, a zero thickness cohesive zone element was established between the first and second layer of composite laminate close to the bolt head. The stress and damage state of the cohesive zone element under different gap filling methods were analyzed.

Figure 17 shows the distribution of the QUADSCRT and SDEG value of the cohesive zone element around the hole. QUADSCRT indicates the stress state of the cohesive zone element while SDEG indicates the damage state of the cohe- sive zone element. As can be seen from the figure, the QUADSCRT value is obvious in two areas, including the hole circumference of the composite laminate $\left(r_{1}=3.175 \mathrm{~mm}\right)$ and the position where the edge of the bolt head is directly pressed $\left(r_{2}=5.565 \mathrm{~mm}\right)$. The composite laminate has geometrical discontinuities due to the bolt hole, so it is easy to have stress concentration and damage around the hole during bolt connection. At the same time, the compressing effect of the bolt head edge area is serious which is easy to form a stress concentration area on composite laminate.

Figures 17(a), 17(d), and 17(g) show the distribution of QUADSCRT values around the hole $\left(r_{1}\right)$ in forced assembly. It can be seen from the figure that there are two peaks in the circumferential direction of the hole when the gap is $0.1 \mathrm{~mm}$ $0.6 \mathrm{~mm}$, which are located in the area of $90^{\circ}$ and $240^{\circ}$. When the gap is $0.8 \mathrm{~mm}-2.0 \mathrm{~mm}$, there are 4 peaks in the circumferential direction of the hole, which are located at $0^{\circ}, 90^{\circ}, 180^{\circ}$, and $240^{\circ}$. This indicates that the distribution of QUADSCRT values along the circumference of the hole is not uniform when the gap is greater than $0.8 \mathrm{~mm}$, and the change behavior is more complicated. The QUADSCRT value distribution becomes more uniform after filling the liquid or peelable fiberglass shim. There are two peaks along the circumference of the hole, which are located in the vicinity of $90^{\circ}$ and $270^{\circ}$, and the peak values are close to or equal to 1 . The difference of QUADSCRT is not obvious with the two kinds of shims. Filling shims cannot reduce the stress value of the interlaminar elements, but it can make the stress distribution more uniform and improve the stress state of interlaminar element.

Figures $17(\mathrm{~b}), 17(\mathrm{e})$, and $17(\mathrm{~h})$ are the distribution diagrams of QUADSCRT at radius $r_{2}$ of composite laminate. It can be seen from the figure that during forced assembly, a total of 4 peaks appear along the hole circumference, 


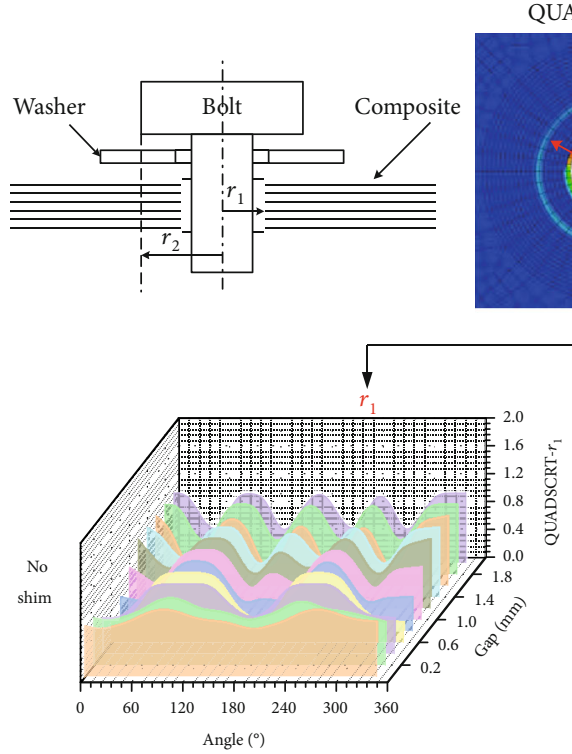

(a)

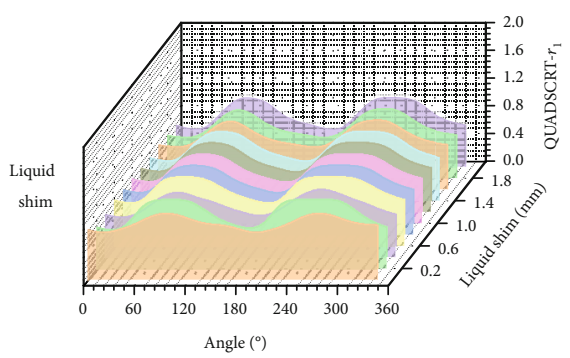

(d)

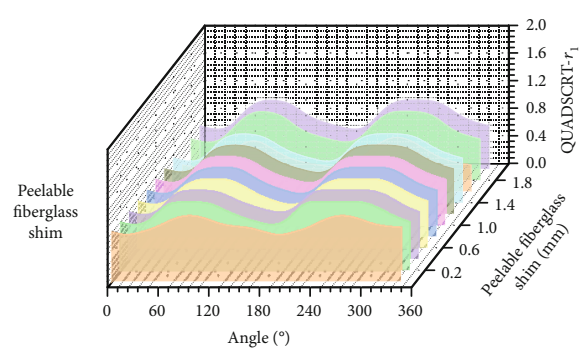

(g)
QUADSCRT
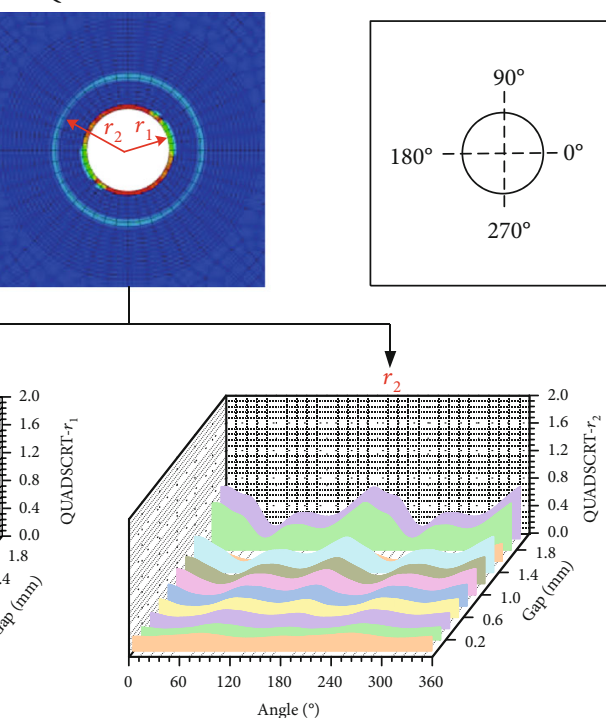

(b)

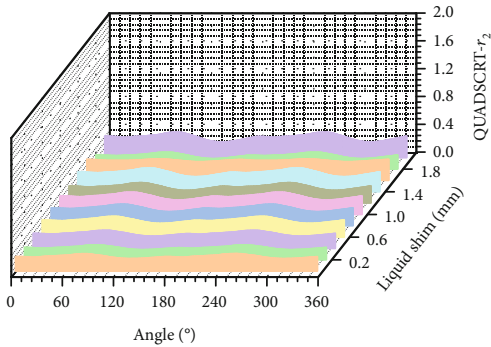

(e)

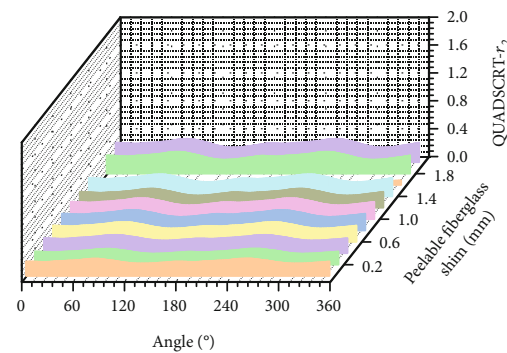

(h)
SDEG
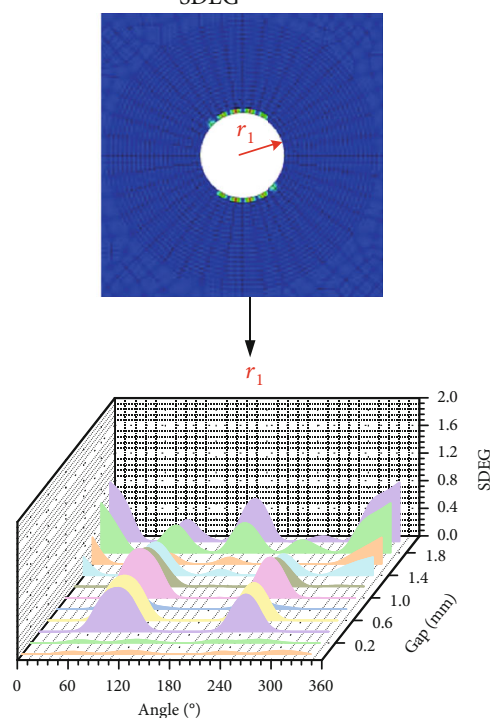

(c)

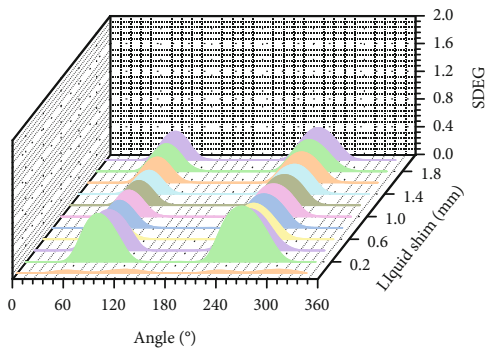

(f)

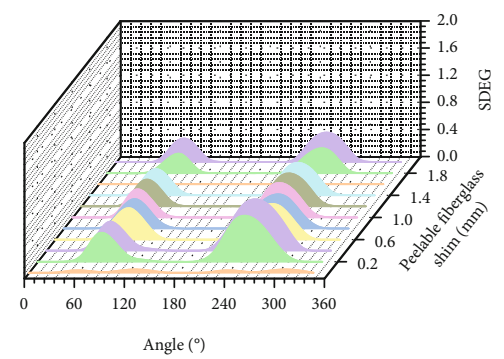

(i)

FIGURE 17: The distribution diagram of QUADSCRT and SDEG in the cohesive zone element of composite laminates around the hole.

located at $0^{\circ}, 90^{\circ}, 180^{\circ}$, and $270^{\circ}$, respectively. The peak value of QUADSCRT increases with the gap. Among them, the value is larger in the direction of $0^{\circ}$ and $180^{\circ}$ than other degree, and the maximum value exceeds 0.7 when the gap is $2.0 \mathrm{~mm}$. The use of liquid shim or peelable fiberglass shim can significantly reduce the QUADSCRT value. The QUADSCRT does not change significantly in different thickness of shim, and the maximum value does not exceed 0.4 .

Figures 17(c), 17(f), and 17(i) are the distribution diagrams of SDEG at the radius $r_{1}$ of composite laminate. It can be seen from the figure that in case of forced assembly, the SDEG is relatively small when the gap is less than $0.4 \mathrm{~mm}$, and two peaks appear at $90^{\circ}$ and $240^{\circ}$ when the gap is greater than $0.4 \mathrm{~mm}$. When the gap is greater than $1.4 \mathrm{~mm}$, other two peaks appear around $0^{\circ}$ and $180^{\circ}$. As liquid shim and peelable fiberglass shim are used, the peaks only appear in the two regions of $90^{\circ}$ and $240^{\circ}$, and the peak value is smaller than that of forced assembly. The obvious stress concentration is produced in the $r_{1}$ position of composite laminate during bolt connection, and the damage factor of the local area in forced assembly is close to 0.8 , so delamination damage may occur prematurely during service and affecting the bearing capacity of the bolted structure. After using liquid shim or peelable fiberglass shim, the damage factor of each area is reduced to about 0.4 , thereby greatly reducing the risk of interlaminar element damage at the edge of hole and ensuring the bearing capacity of bolted structure.

\section{Conclusions}

This paper studied the influence of assembly gap and shims on the strain and stress state of the composite-aluminum 
assembly structure. An experimental device was designed to simulate the application of the bolt preload, the strain gauge measurement experiment and 3D-DIC measurement experiment were performed, and the surface strain information of specimen was obtained. A finite element model was established in ABAQUS, while the interlaminar stress and damage state of composite laminate were analyzed using zero thickness cohesive zone elements. The conclusions include

(1) During forced assembly, the strain of composite laminate and aluminum plate is mainly affected by bending deformation and bolt head compression. With the continuous increase of gap, the strain value of each measuring point continues to increase. The strain of the specimen in the $X$-direction is mainly affected by the bending deformation, and the strain in the $Y$-direction is mainly affected by the compression of the bolt head. The strain value on the surface of the composite laminate is greater than that of the aluminum plate, so the deformation of the composite laminate is more serious

(2) The shim filling has increased the deformation of the compression zone, but significantly decreased the strain caused by the bending deformation of the specimen. The shims can smooth the strain distribution in the gap filling area. Shims can significantly reduce the strain value in the $X$-direction of the specimen. As the thickness of shims increase, the magnitude of the strain reduction also increases significantly. When the shim thickness is $0.2 \mathrm{~mm}$, the strain value of composite laminate can be reduced by at least $8.31 \%$. As the shim thickness is $2.0 \mathrm{~mm}$, the strain value can be reduced by $70.97 \%$ at most. For the strain value in the $Y$-direction, the liquid shim can only reduce it when the gap is large, and the surface strain of the composite laminate can be reduced by up to $23.93 \%$. Peelable fiberglass shim increases the surface strain of specimen in most cases

(3) The zero thickness cohesive zone elements were established between the first and second layer of composite laminate close to the bolt head. The stress and damage state of the cohesive zone element under different gapfilling methods were analyzed. It can be seen that the QUADSCRT value is obvious in two areas, including the hole circumference of the composite laminate $\left(r_{1}=3.175 \mathrm{~mm}\right)$ and the position where the edge of the bolt head is directly pressed $\left(r_{2}=5.565 \mathrm{~mm}\right)$. The SDEG value is obvious in the hole circumference of the composite laminate $\left(r_{1}=3.175 \mathrm{~mm}\right)$. The liquid shim and peelable fiberglass shim cannot reduce the stress value of the interlaminar elements, but it can make the stress distribution more uniform and improve the stress state of the interlaminar element after $0.8 \mathrm{~mm}$. After using liquid shim or peelable fiberglass shim, the damage factor in each area is reduced to about 0.4 , and the distribution is more uniform. Thereby, the shim can greatly reduce the risk of interlaminar element damage at the edge of hole and ensuring the bearing capacity of bolted structure

\section{Data Availability}

The data used to support the findings of this study are available from the corresponding author upon request.

\section{Conflicts of Interest}

Authors declare that there are no conflicts of interest regarding publication of this article.

\section{Acknowledgments}

The authors wish to acknowledge the National Natural Science Foundation of China (51975280), National Commercial Aircraft Manufacturing Engineering Technology Research Center Project (COMAC-SFGS-2018-3008), and the support from the China Scholarship Council (No. 201906830013). Moreover, the authors would like to acknowledge the editors and the reviewers for their insightful comments.

\section{References}

[1] G. Marsh, "Airbus A350 XWB update," Reinforced Plastics, vol. 54, no. 6, pp. 20-24, 2010.

[2] R. M. Coleman, The Effects of Design, Manufacturing Processes and Operations Management on the Assembly of Aircraft Composite Structure, [Ph.D. thesis], Massachusetts Institute of Technology, 1991.

[3] K. Manohar, T. Hogan, J. Buttrick, A. G. Banerjee, J. N. Kutz, and S. L. Brunton, "Predicting shim gaps in aircraft assembly with machine learning and sparse sensing," Journal of Manufacturing Systems, vol. 48, pp. 87-95, 2018.

[4] C. Lacroix, L. Mathieu, F. Thiébaut, M. Douilly, and H. Falgarone, "Numerical process based on measuring data for gap prediction of an assembly," Procedia CIRP, vol. 27, pp. 97-102, 2015.

[5] H. Falgarone, F. Thiébaut, J. Coloos, and L. Mathieu, "Variation simulation during assembly of non-rigid components. Realistic assembly simulation with ANATOLEFLEX software," Procedia CIRP, vol. 43, pp. 202-207, 2016.

[6] F. Ehmke, S. Rao, and J. Wollnack, "Single step shimming solution for automated aircraft assembly," in 13th IEEE Conference on Automation Science and Engineering, pp. 662-667, Xi'an, China, August 2017.

[7] F. Schmick, N. O. Lüders, and J. Wollnack, "Automated assembly of large CFRP structures: adaptive filling of joining gaps with additive manufacturing," in 2016 IEEE International Symposium on Assembly and Manufacturing, pp. 126-132, Fort Worth, TX, USA, August 2016.

[8] N. Zaitseva, S. Lupuleac, M. Petukhova, M. Churilova, T. Pogarskaia, and M. Stefanova, "High performance computing for aircraft assembly optimization," in 2018 Global Smart Industry Conference, pp. 1-6, Chelyabinsk, Russia, November 2018.

[9] O. J. Bakker, A. A. Popov, and S. M. Ratchev, "Variation analysis of automated wing box assembly," Procedia CIRP, vol. 63, pp. 406-411, 2017.

[10] Q. Wang, Y. D. Dou, L. Cheng, and Y. L. Ke, "Shimming design and optimal selection for non-uniform gaps in wing assembly," Assembly Automation, vol. 37, no. 4, pp. 471-482, 2017. 
[11] X. Liu, J. Chang, Y. Yang, Y. Wang, Y. Bao, and H. Gao, "Evaluation of assembly gap from 3D laser measurements via FEA simulation," International Journal of Aerospace Engineering, vol. 2018, Article ID 4303105, 7 pages, 2018.

[12] G. D'Angelo, G. Cavaccini, and S. Rampone, "Shimming analysis of carbon-fiber composite materials with eddy current testing," in 2018 5th IEEE International Workshop on Metrology for AeroSpace, pp. 68-73, Rome, Italy, June 2018.

[13] Q. Wang, Y. Dou, J. Li, Y. Ke, P. Keogh, and P. G. Maropoulos, "An assembly gap control method based on posture alignment of wing panels in aircraft assembly," Assembly Automation, vol. 37, no. 4, pp. 422-433, 2017.

[14] C. S. Dong and L. Kang, "Deformation and stress of a composite-metal assembly," The International Journal of Advanced Manufacturing Technology, vol. 61, no. 9-12, pp. 1035-1042, 2012.

[15] R. Söderberg, K. Wärmefjord, and L. Lindkvist, "Variation simulation of stress during assembly of composite parts," CIRP Annals, vol. 64, no. 1, pp. 17-20, 2015.

[16] J. H. Chang, X. S. Liu, Y. X. Yang, Y. Q. Wang, and H. Gao, "The influence of the assembly gaps and tightening operations on the stress distribution during the assembly process," in IOP Conference Series: Materials Science and Engineering, pp. 1-5, Dalian, China, July 2018.

[17] J. H. Chang, Y. X. Yang, X. S. Liu, H. Gao, and Y. Q. Wang, "A mixed shimming method in eliminating the gaps during the assembly process of the complex structures," in IOP Conference Series: Materials Science and Engineering, pp. 1-4, Sanya, China, November 2018.

[18] C. Y. Attahu and L. L. An, "Influence of assembly gap and shims on the strain and stress of bolted composite-aluminum structures," ARPN Journal of Engineering and Applied Sciences, vol. 12, no. 5, pp. 1593-1619, 2017.

[19] X. Ye, L. L. An, X. D. Yue, and G. Q. Gao, "Effect of gap-filling compensation on mechanical properties of carbon fiber/epoxy resin composite-aluminum assembly structure," Acta Materiae Compositae Sinica, vol. 37, pp. 2183-2199, 2020.

[20] Y. N. Zhai, D. S. Li, X. Q. Li, and L. Wang, "An experimental study on the effect of joining interface condition on bearing response of single-lap, countersunk composite-aluminum bolted joints," Composite Structures, vol. 134, pp. 190-198, 2015.

[21] Y. N. Zhai, X. Q. Li, L. Wang, and D. S. Li, “Three-dimensional layer-by-layer stress analysis of single-lap, countersunk composite joints with varying joining interface conditions," Composite Structures, vol. 202, pp. 1021-1031, 2018.

[22] L. Liu, J. Zhang, K. Chen, H. Wang, and M. Liu, "Experimental and numerical analysis of the mechanical behavior of composite- to-titanium bolted joints with liquid shim," Aerospace Science and Technology, vol. 49, pp. 167-172, 2016.

[23] L. Liu, "The influence of the substrate's stiffness on the liquid shim effect in composite-to-titanium hybrid bolted joints," Proceedings of the Institution of Mechanical Engineers, Part G: Journal of Aerospace Engineering, vol. 228, no. 3, pp. 470479, 2013.

[24] A. J. Comer, J. X. Dhôte, W. F. Stanley, and T. M. Young, "Thermo-mechanical fatigue analysis of liquid shim in mechanically fastened hybrid joints for aerospace applications," Composite Structures, vol. 94, no. 7, pp. 2181-2187, 2012.

[25] C. Hühne, A. K. Zerbst, G. Kuhlmann, C. Steenbock, and R. Rolfes, "Progressive damage analysis of composite bolted joints with liquid shim layers using constant and continuous degradation models," Composite Structures, vol. 92, no. 2, pp. 189-200, 2010.

[26] J. X. Dhôte, A. J. Comer, W. F. Stanley, and T. M. Young, "Study of the effect of liquid shim on single-lap joint using 3D digital image correlation," Composite Structures, vol. 96, pp. 216-225, 2013.

[27] Y. X. Yang, X. S. Liu, Y. Q. Wang, H. Gao, Y. J. Bao, and R. P. $\mathrm{Li}$, "An enhanced spring-mass model for stiffness prediction in single-lap composite joints with considering assembly gap and gap shimming," Composite Structures, vol. 187, pp. 18-26, 2018.

[28] Y. X. Yang, Y. Q. Wang, X. S. Liu, H. Gao, and Y. J. Bao, “The effect of shimming material on flexural behavior for composite joints with assembly gap," Composite Structures, vol. 209, pp. 375-382, 2019.

[29] L. Cheng, Q. Wang, and Y. L. Ke, "Experimental and numerical analyses of the shimming effect on bolted joints with nonuniform gaps," Proceedings of the Institution of Mechanical Engineers, Part C: Journal of Mechanical Engineering Science, vol. 233, no. 11, pp. 3964-3975, 2019.

[30] C. Y. Attahu, L. L. An, Z. Q. Li, and G. Q. Gao, "Influence of shim layers on progressive failure of a composite component in composite-aluminum bolted joint in aerospace structural assembly," Transactions of Nanjing University of Aeronautics and Astronautics, vol. 35, no. 1, pp. 188-202, 2018.

[31] E. J. Landström, Influence of Liquid Shim on the Bearing Strength of a Composite Bolted Joint, KTH, 2019.

[32] C. Stocchi, Investigation on the Mechanical Behaviour of Single-Lap Composite Joints with Countersunk Bolts, [Ph.D. thesis], Imperial College London, 2013.

[33] A. Sellitto, S. Saputo, A. Russo et al., "Numerical-experimental investigation into the tensile behavior of a hybrid metallicCFRP stiffened aeronautical panel," Applied Sciences, vol. 10, no. 5, pp. 1-18, 2020.

[34] R. Matsuzaki, M. Shibata, and A. Todoroki, "Improving performance of GFRP/aluminum single lap joints using bolted/co-cured hybrid method," Composites Part A: Applied Science and Manufacturing, vol. 39, no. 2, pp. 154-163, 2008.

[35] A. Riccio, A. Russo, A. Sellitto, C. Toscano, D. Alfano, and M. Zarrelli, "Experimental and numerical assessment of fibre bridging toughening effects on the compressive behaviour of delaminated composite plates," Polymers, vol. 12, no. 3, pp. 1-20, 2020.

[36] J. P. Davim and P. Reis, "Study of delamination in drilling carbon fiber reinforced plastics (CFRP) using design experiments," Composite Structures, vol. 59, no. 4, pp. 481-487, 2003.

[37] A. Russo, M. Zarrelli, A. Sellitto, and A. Riccio, "Fiber bridging induced toughening effects on the delamination behavior of composite stiffened panels under bending loading: a numerical/experimental study," Materials, vol. 12, no. 15, pp. 1-14, 2019.

[38] D. ASTM, D5961/D5961M: Standard Test Method for Bearing Response of Polymer Matrix Composite Laminates, American Society for Testing and Materials, 2008.

[39] G. Bresson, J. Jumel, M. E. R. Shanahan, and P. Serin, "Statistical aspects of the mechanical behaviour a paste adhesive," International Journal of Adhesion and Adhesives, vol. 40, pp. 70-79, 2013.

[40] E. T. Camponeschi Jr., R. E. Bohlmann, and J. H. Fogarty, "Composite to metal joints for the ARPA man-rated 
demonstration article," Journal of Thermoplastic Composite Materials, vol. 8, no. 1, pp. 56-79, 2016.

[41] T. Ireman, "Three-dimensional stress analysis of bolted singlelap composite joints," Composite Structures, vol. 43, no. 3, pp. 195-216, 1998.

[42] G. Kelly and S. Hallström, "Bearing strength of carbon fibre/epoxy laminates: effects of bolt-hole clearance," Composites Part B: Engineering, vol. 35, no. 4, pp. 331-343, 2004.

[43] C. Inc, "CYCOM 977-2 Epoxy Resin System Data Sheet," 2012, https://www.cytec.com/sites/default/files/datasheets/ CYCOM_977-2_031912.pdf.

[44] G. Alfano, "On the influence of the shape of the interface law on the application of cohesive-zone models," Composites Science and Technology, vol. 66, no. 6, pp. 723-730, 2006.

[45] L. Ye, "Role of matrix resin in delamination onset and growth in composite laminates," Composites Science and Technology, vol. 33, no. 4, pp. 257-277, 1988.

[46] A. Ataş and C. Soutis, "Strength prediction of bolted joints in CFRP composite laminates using cohesive zone elements," Composites Part B: Engineering, vol. 58, pp. 25-34, 2014. 